

\title{
Community-based and pro-poor tourism: Initial assessment of their relation to community development
}

\author{
Melville Saayman ${ }^{1 *}$ and Andrea Giampiccoli ${ }^{2}$
}

Received: 20/04/2015 Accepted: 11/09/2015

\begin{abstract}
1 Director TREES (Tourism Research in Economic, Environs and Society), North-West University, (Potchefstroom Campus), Private Bag X6001, Box 204, Potchefstroom, 2520, South Africa; tel: +27 (0)18 299 4140; fax +27 (0)18 299 4140; e-mail: Melville.Saayman@nwu.ac.za

${ }^{2}$ Research Associate, Hospitality and Tourism Department (Ritson Campus), Durban University of Technology, PO Box 1334, Durban, 4000, South Africa; tel: +27 (0)31 37330 22; fax: +27(0)31 37355 02; e-mail: andrea.giampiccoli@gmail.com

* Corresponding author
\end{abstract}

\begin{abstract}
Alternative forms of tourism development from its conventional approach such as community-based tourism (CBT) and pro-poor tourism (PPT) are proposed to be specifically relevant to alleviate poverty and facilitate the development of disadvantaged community members. The intention of this review paper is to show, despite an apparent similarity, that there are indeed substantial differences between CBT and PPT. While CBT is an alternative to conventional mass tourism and it prioritises control by disadvantaged community members and the benefits of the tourism sector within a social justice perspective with redistributive aims, PPT originated, sustained and is sustained by the neoliberal system and its work does not offer great possibilities of changing the status quo. This, in effect, increases the inequality gap. The paper concludes that the tourism sector properly and holistically fosters social justice and redistributive measures to decrease the inequality gap and further proposes PPT strategies needed to take a CBT direction guiding the tourism sector as a whole.
\end{abstract}

(C) 2016 Varna University of Management. All rights reserved

Keywords: Empowerment, community development, tourism development, poverty reduction

Citation: Saayman, M., A. Giampiccoli (2016) Community-based and pro-poor tourism: Initial assessment of their relation to community development. European Journal of Tourism Research 12, pp. $145-190$

\section{Introduction}

For a substantial period, it has been proposed that 'capitalism had become a world system' (Barratt Brown, 1995; De Martino, 2003) and neoliberal discourse has become ubiquitous in interpreting how life is understood (Harvey, 2007). Globally, there is an increase in inequality in both developed and developing countries and the unequal distribution of factors such as power, wealth and education is likely to grow (Zajda, 2011). Objections can be made to the supposition that neoliberalism decreases inequality (see Hunter Wade, 2004:583). 
Duffy (2014:90) proposed 'neoliberalism as a 'nebuleuse' of ideas, institutions and organizations that create conditions favourable to neoliberalism, so that it appears as natural, neutral and as if there is no alternative.' Thus, the last 20 years have witness 'the global expansion of neoliberalism, including the rollback of states coupled with a roll forward of new forms of regulation to facilitate private interests, the expansion of market based mechanisms to new natural resources such as water and genetic material, as well as the privatisation of public services' (Duffy, 2014:91). Neoliberalism's belief is based on free-market, private property, individualism and decrease of state intervention (see also Higgins-Desbiolles, 2006). It can also imply a global institution perspective, the glossary explication of neo-liberal ideas as written in the glossary presented in the UN system (specifically in the World Health organisation $\mathrm{WHO}$ ) website (WHO, no date):

This is the philosophy that underpins and drives economic globalization. At its core is a belief in the free market and minimum barriers to the flow of goods, services and capital. It is an extension of the traditional liberal philosophy, which argues for a separation of politics and economics and that markets should be "free" from interference of government. This approach is based on four principles:

- Economic growth is paramount: corporations and their agents need to be free to pursue whatever gives them an economic advantage and, in consequence, internal and global markets must be free to operate with little government constraint or regulation.

- $\quad$ Free trade benefits all nations - rich or poor - because every nation has a comparative advantage.

- Government spending creates inefficiency and waste: although most neoliberals agree that not all public expenditure is wasteful, many argue that it can be reduced.

- In the distribution of economic goods, individual responsibility replaces the concepts of public goods and community.

- There are four pillars to the neo-liberal approach all of which involve liberalization (the reduction of rules and restrictions): capital account liberalization, trade liberalization, domestic liberalization, and privatization.

When considered neoliberalism as a hegemonic process of globalisation (see Giampiccoli, 2007; Higgins-Desbiolles, 2006) specific class(es) or group(s) can specifically benefit. Finally to note that lately has been suggested that 'there has been surprisingly little attention to the specific inter-relationships between tourism and neoliberalism' (Duffy, 2014:89) giving, therefore, still more relevance to the present paper.

The issue at hand is to understand whether proposed alternative forms of tourism development such as pro-poor tourism (PPT) and community-based tourism (CBT) can be used towards the fulfilment of the neoliberal plan, or to oppose it. Therefore, it is important to understand the positioning of PPT and CBT in relation to the current neoliberal milieu and matters of poverty reduction and community development. Within this context, specific issues of ideology, discourse, policies and related matters in general and their correlation to tourism need to be considered and sketched out as the background required for the complete comprehension of this paper. Different issues related to PPT and CBT will be examined and specific sections will focus on matters of collective management and scale of impact.

Alternative forms of tourism development should not be seen as a panacea for poverty reduction and community development in disadvantaged communities. However, it is relevant to understand firstly how the tourism sector, as a major economic global industry, is related to these global disparities and how specific tourism strategies (in this case, PPT and CBT) are correlated with, or against, these inequalities and the imbalanced distribution development approaches. This review paper will propose differences between CBT and PPT in relation to community development in the current global milieu.

The present paper leans towards a criticism of the globalisation framework; however, as with 
Peet (2003), it deals 'with neo-liberal globalization, not just globalization as a neutral spatial process [...] neo-liberal globalization is the focus of our critique, not globalization in general, and certainly not as potential.' This paper is relevant because changes in the structure of tourism (and of society) are foreseen as necessary to improve the living conditions of already disadvantaged communities. In this context it has also been to recognised that although currently less prolific communist, mercantilist, social democratic system of political economy can be linked to tourism development and globalization (see Webster \& Ivanov, 2013; see also Webster \& Ivanov 2012 on various political economy approaches in tourism).

\section{It may perhaps be better expressed by saying:}

If persistent structural inequities are not addressed, relying on tourism (pro-poor or not) as a last resort 'rescue plan' is unlikely to reap significant and long-term benefits for the already marginalised, particularly if their communities are already fractured and inhabit environmentally vulnerable areas (Chok, Macbeth, \& Warren, 2007).

Based on the above, this paper has the following objectives:

- Firstly to contextualise the relationship between tourism, development and the current global economic neoliberal framework;

- Secondly, to review CBT in relation with (as well as its role in) community development within neoliberalism;

- Thirdly, to analyse PPT in relation to community development within neoliberalism;

- Fourthly, to investigate CBT's scale of impact, collective entrepreneurship and implementation approach from a PPT perspective; and

- Lastly, to propose a different positioning of CBT and PPT in relation to community development.

The tourism sector is within the 'global neoliberal market economy' (Chok et al., 2007). Therefore, the working context of tourism development in relation to poverty reduction and community development must remain within the context of the current neoliberal framework. Within neoliberalism, 'the argument that tourism can serve as an effective povertyfighting strategy is premised on two distinct, though frequently assumed, relationships. The first is that tourism development indelibly leads to economic growth, and the second is that economic growth can effectively reduce poverty' (Gartner \& Cukier, 2012). At the same time (or consequently), tourism can promote the development of a 'culture of servitude' (Faulkenberry, Coggeshall, Backman, \& Backman, 2000) and can produce inequality by its continuous and seemingly unstoppable expansion (Cole \& Morgan, 2010). Elaborate models to measure the impact of tourism on the economy have been proposed, suggesting 'the contribution of tourism to the economy is proportional to the benefits experienced by local populations', but these macroeconomic measures do not properly show the poverty realities at household level (Gartner \& Cukier, 2012).

Although not considered in detail in this paper, it should be borne in mind that 'underdevelopment' can be seen as a specific conceptual construct elaborated upon by specific actors and that it is largely based on Western capitalist-based conceptualisation (Adams, 2001). Here, it is opined that underdevelopment is based on the condition of dependency to which specific sector(s) of society and/or countries are maintained through the capitalist system. This follows from the idea that, 'it is capitalism, both world and national, which produced under development in the past and which still generates underdevelopment in the present' (Frank, 1969). This long-standing assumption seems valid even today explaining that, 'contemporary underdevelopment is in large part the historical product of past and continuing economic and other relations between the satellite underdeveloped and the now developed metropolitan countries. Furthermore, these relations are an essential part of the structure and development of the capitalist system on a world scale as a whole' (Frank, 1966). Studying the tourism sector, De Kadt (1979:38), some time ago, proposed similar development issues relevant to tourism: 'First is the realisation that 
growth alone may not suffice to overcome poverty within a reasonable time, and that the distribution of the material benefits of development among the poorest countries and the poorest populations groups within individual countries requires special attention [...] The second area of discussion deals with the supposed causes of worldwide inequality and the working of the international economic system. The contention is that no development strategy can hope to be successful without a restructuring of North-South economic relations as regards, for example, trade, investment, and transfer of technology [...] Third, 'one -world' arguments question whether the pursuit by all countries of rapidly rising mass consumption will be feasible for much longer, given the consequent environmental deterioration and looming exhaustion of non-renewable natural resources.'

Therefore, the elimination of poverty 'should not be regarded as 'charity' - the domain of 'bighearted' pop stars or 'enlightened' bureaucrats' (Chok, et al., 2007:160), but it should comprise a restructuring of the society towards the more just and equitable distribution of power/control, resources, knowledge, capacities and benefits. As a consequence, and although not fashionable today, tourism and political economy have to be reconnected as the political economy still has to offer insights into tourism analysis (Mosedale, 2010; Bianchi, 2009; 2011).

The role of tourism in capitalist accumulation should go beyond the economic milieu to include political and geographical matters (Britton, 1991). Tourism must be understood as 'an essentially political concept' that is linked to economic, social and political issues of development (Hall, 1998). The tourism sector as a whole should be understood in its globallocal nexus within the 'the prevailing discourse on internationalization and globalization' (Milne \& Ateljevic, 2001). In addition it must be consider that globalisation and tourism destination are 'proportionally' linked. As such 'The process of globalisation and the resulting levels of globalisation of a destination could be considered as a driver of destination competitiveness, because it facilitates travel to and stay in the destination. More globalised destinations should be more competitive on the tourist market as they would have fewer restrictions to foreign travellers and investors' (Ivanov\& Webster, 2013a:628; see also Ivanov \& Webster, 2013b on similar issues of globalization in relation to tourism and growth). Thus, while 'Globalisation of a country can be used as a driver of its competitiveness-a destination can become more competitive when it is more open to the world in economic, social, and political aspects" (Ivanov\& Webster, 2013a:631) caution is needed. As such 'globalisation should not be embraced unconditionally [...] the level of globalisation of the country does not necessarily mean that its tourism industry would increase the economic welfare of the local population' (Ivanov\& Webster, 2013a:631; see also Ivanov \& Webster, 2013b on similar issues).

At the same time the issue should not to embrace or not globalization (globalization is difficult/unrealistic to avoid) but should be approached in a manner that considers local context and population as a main value. As such it is here proposed - following what time ago proposed from Tanzania - what could be seen as one possible alternative pattern to neoliberal-competitive and individualistic approach of globalization. Thus, cooperation and self-reliance (but not isolationism) could be give an option when proposing the need of 'spreading the concept of working together cooperatively for the common good instead competitively for individual private gain' and at the same time advance self-reliance in such a way that 'does not imply isolationism, either politically or economically. It means that we shall depend on ourselves, not on others. But this is not the same thing as saying we shall not trade with other people or co-operate with them when it is to mutual benefit' (Nyerere, 1974: 102, 99).

Linked to these issues, this analysis supports the fact that within the current neoliberal globalisation and actual tourism working structures, tourism development is not facilitating benefits to poor communities, it is externally owned and controlled, and perpetuates inequality and the exploitation of local resources and people (Wearing \& McDonald, 2002). Conventional mass tourism 
is not working towards more distributive measures. Therefore, as Khan (1997) proposed some years ago (but apparently with current validity), 'if mass tourism promotes economic growth and development, then how come many tourist-receiving Third World countries $[\ldots]$ are suffering from foreign dependency along with persistent poverty, economic inequality, and destruction of cultures and communities in the name of tourism development?' Interestingly, in an elucidative paper focusing on the South Africa context, Saayman, Rossouw and Krugell (2012) proposed that growth in tourism, in fact, can have a negative impact on the poorest strata of society if specific actions (in this case, especially in education) are not taken. Here, it can be proposed that tourism seems to generate a 'trickle-up' effect as the 'trickledown' effect seems to work only in relation to (in favour of) the middle and upper classes, instead of reaching the poor. Gartner and Cukier (2012:561) also propose that tourism development does not necessarily mean poverty reduction and in fact "under certain conditions, may even perpetuate or exacerbate poverty'.

Community development must be understood as a concept developed since the time of the writing of Seers (1969), thereby going beyond strict numerical data, but including matters associated with self-reliance (Sharpley, 2002), freedom (Goulet, 1971) and empowerment (Sofield, 2003), and inculcating a general improvement of quality of life (Saayman, 2009). Following this new understanding of development, including such aspects as empowerment, self-reliance and sustainability, is the basis of this paper. Matters of empowerment, self-reliance and sustainability at individual and community level are seen as central to the community development process. Self-reliance 'is located centrally within the discourse of community development and is connected to related concepts like self-help, mutual-help, indigenous participation and rural development' (Fonchingong \& Fonjong, 2003). At the same time, 'a community-based approach to tourism development is a prerequisite to sustainability' (Woodley, in Tosun, 2000). Empowerment is seen as a basic condition for holistic development
(Scheyvens, 1999, 2002; Sofield, 2003; Reid 2003). Empowerment, social justice and human diversities should all be present in community development and a community-based approach should include all of these (Ife, 2002). Sofield (2003) argues that it is difficult to attain sustainable development without empowering communities. Echoing Frank's (1988) discussion of metropolis-satellite relationships, Sofield (2003:74) also mentions that as the greater dependency of powerless groups has increased, so has the difficulty for those groups to work independently towards a re-balance of power, whereas '[w]here the subordinate party has a degree of autonomy, the less need for the powerful party and its resources, hence a greater capacity to rejects its power and to enter into relation with others'.

The arguments highlighted in this section form the general framework within which the subsequent sections should be understood.

\section{Community-based tourism (CBT)}

This section relates to the second objective of this review and it proposes CBT's relationship with (and role in) community development within the context of neoliberalism. The section presents, within the general framework of neoliberalism, CBT's origin, different interpretations, the mismatch between theory and practice of $\mathrm{CBT}$, various characteristics and pre-conditions of $\mathrm{CBT}$, issues on control of CBT development, as well as the role of external actors in CBT.

The aim of the paper is not to specifically explore pros and cons of CBT (and PPT) but it is to investigate their positioning in relation to community development within the current neoliberal milieu. However, it is necessary to anticipate that this paper lean in favour of CBT. Very importantly, this does not mean that CBT is seen as a panacea in tourism and community development. CBT has various obstacles, challenges, problems and limitations. It is also possible to distinguish between CBT endogenous and exogenous produced problems and limitations. Ostrom (2000:153) also refers to other literature to illustrate that as with other forms of economic and political organisation, community selforganized forms of organisation, are vulnerable to both exogenous and endogenous factors 
and threats. In CBT development some problems are intrinsic to CBT itself, while others are products of their inclusion in the neoliberal structure of tourism industry and, in some case, international cooperation. Some of these challenges and problems in CBT development will be mentioned in the paper.

\section{Historical background and definitional issues of CBT}

Despite some authors (Asker, Boronyak, Carrard, \& Paddon 2010) proposing that, '[t]he term Community Based Tourism (CBT) emerged in the mid-1990s'; its conceptual origin and the term would appear to be an antecedent of the 1990s. CBT background origin, as a part of the community-based development strategy, can be traced back to the alternative development milieu of the 1970s (Cornelissen, 2005; Giampiccoli \& Mtapuri, 2012; Karim, Mohammad \& Serafino, 2012; Mitchell \& Muckosy, 2008; Ruhiu, 2007; Telfer, 2009; Zapata, Hall, Lindo, \& Vanderschaeghe, 2011). The term CBT had already been used during the early 1980s in Canada by the Department of Economic Development and Tourism, Government of the Northwest Territories (NWT, 1983; Getz, in Murphy \& Andressen, 1988). Finally, in 1979, de Kadt (1979) mentions the case of a community cooperative run guesthouse and mentions the community-based approach.

Despite its relative longevity, CBT struggles to find a common definition, interpretation and modus operandi (Kiss, 2004; Mayaka, croy, \& Mayson, 2012; Ndlovu \& Rogerson, 2003). Consequently, various models and interpretations related to $\mathrm{CBT}$ have been proposed (Giampiccoli \& Mtapuri, 2012; Harris, 2009; Häusler \& Strasdas, 2003; Mtapuri \& Giampiccoli, 2013; Naguran, 1999; Okazaki; 2008; Pinel 1999; Simpson, 2008; Zapata et al., 2011). Furthermore, CBT ventures should be understood as falling mostly within the realm of community-based enterprises (CBEs) (see, for example Mtapuri \& Giampiccoli, 2013; Calanog, Reyes, \& Eugenio, 2012; Manyara \& Jones, 2007).

\section{Neoliberalism and CBT theories and practices}

CBT's theoretical intentions and practices (genuine or not) often do not support the 150 promotion of real empowerment. It seems that, '[w] hile the rhetoric suggests that there is much support for CBET [community-based ecotourism] ventures, in practice it is difficult to find good examples of this' (Scheyvens, 2002:72). However, the potential of CBT is still recognised and its development should be facilitated instead of surrendering to an improper approach or lack of capacity and resources (Moscardo, 2008; Scheyvens, 1999). It should be noted that CBT has recently been reported as, 'gaining popularity as a strategy for environmental conservation and social inclusion' and numerous programmes are in place in many countries to this effect (Baktygulov \& Raeva, 2010). Many CBT studies are present in the literature (LópezGuzmán, Sánchez-Cañizares, \& Pavón, 2011) and various positive examples of CBT are present around the world (Nyaupane, Morais, \& Dowler, 2006; Asker, et al., 2010; Mielke, 2012 for Brazil; Baktygulov \& Raeva, 2010 for Kyrgystan, Kontogeorgopoulos, Churyen, \& Duangsaeng, 2014 for Thailand).

Partly due to its different interpretations, CBT suffers much criticism (Mayaka et al., 2012). However, it is here proposed that criticism is based on three concurring factors:

1. The different understandings and interpretations of CBT per se;

2. The influence of neoliberal globalisation on CBT; and

3. The basic differences (possibly opposition) in which critics of CBT posit themselves in the development approach debate.

As such, the judgment of the success or otherwise of CBT can depend on the expectations and perspectives/interpretations of CBT (Kontogeorgopoulos et al., 2014).

CBT literature has been seen as divergent from the perspective of social justice. Blackstock (2005) properly argues that while CBT presents a clear parallel with issues of community development such as community control, social justice and mutual respect where 'community development explicitly seeks to dismantle structural barriers to participation and develop emancipatory collective responses to local issues', the advocates of CBT diverge from 
these propositions in three ways: firstly, CBT is not transformative and remains industry friendly; secondly, communities are not recognise in their heterogeneous entities; and thirdly, issues on constraints of local control are not recognised (Blackstock, 2005).

Blackstock (2005:41) writes that 'CBT literature is focused on sustaining the tourism industry, unlike community development's commitment to social justice and empowerment. Proponents do not challenge or question the development of a tourism industry, but seek to make tourism more acceptable to the local residents'. These correct criticisms proposed by Blackstock (2005) to advocates of CBT should, however, be associated to interpretations and strategies of CBT influenced and controlled by, and remaining within, the neoliberal framework. These are directed toward the concepts and practices of CBT that have been shifted, reelaborated, misinterpreted and used as camouflage by neo-liberalism. Blackstock (2005:46) also seems to propose a similar angle when in its conclusion suggests 'CBT is influenced by, and must be aware of, existing structural inequalities, globally and locally'. Therefore, one could argue a need to understand the relationship between community participation and power structures to advance more empowering and socially just understandings of CBT (Blackstock, 2005).

It is suggested here that CBT is not a 'friend' of the neoliberal agenda, but that CBT's conceptual and practical milieu has been shifted/hijacked by the neoliberal agenda in theory and in practice (Giampiccoli \& Mtapuri, 2012). Instead, as Blackstock (2005) seems to agree, the radical changes to the structure of the tourism sector towards more social justice and equity are intrinsically at the heart of CBT's aim. This is the understanding that an advocate and the literature of CBT should follow, instead of the neoliberal approach to CBT. Zapata et al. (2012), for example, show how neoliberalism can influence the connotation, outcome and judgement associated with CBT development. CBT strategies, on the other hand, are well within holistic community development towards a comprehensive restructuring of the tourism sector in line with social justice, equity, community control and their ilk. At the same time, the restructuring of tourism, as a major global sector, should contribute in aiding the restructuring of the society as a whole from a more people-centred and equitable perspective.

Briefly and generally, it is possible to outline how these issues are recognised when it is acknowledged that, as 'presented in the 1990s, CBT differs from general community development theory and process in that it does not have the transformative intent of community development and does not focus on community empowerment' (Beeton, 2006:50). In relation to globalisation, CBT and neoliberalism, it is worth emphasising a number of already suggested points (Pleumaron, 2002). Firstly, and despite the terminology, CBT is controlled by hegemonic global actors; secondly, alternative tourism was 'not problem-free', but it was sincerely controlled by local community members; thirdly, globalised CBT is different from previous types of community-based alternative tourism, particularly in relation to issues of ownership. For example, '[l]ocal people are no longer right holders in projects but have been degraded to 'stakeholders', ostensibly on 'equal' footing with other stakeholders ranging from (inter-) governmental bodies and industry to a great number of brokers, operating at the international, national and local level' (Pleumaron, 2002).

There is a debate related to issues of bottomup and top-down approach in tourism development for the local benefits (see $\mathrm{Li}$, 2006). In this regard, Li (2006) proposes local community members are benefitting from tourism development even in context of weak participation. Whereas, Zapata et al. (2011:4) suggest that their 'research will argue how the negative effects described above are related not to CBT per se but to a top-down development model supported by many international organisations, while a bottom-up CBT presents different characteristics and more hopeful results'. CBT can also be seen as negative in its judgment; therefore, CBT's interpretations, practices and judgments are not of CBT itself, but are based on the hegemonic neoliberal discourse that misinterprets CBT (Zapata et al., 2011). 
The hegemony-discourse framework, of course, specifically gives advantage to specific actors. As a concluding argument here, it is possible to follow the case study of CBT in Kenya, as proposed by Manyara and Jones (2007), who summarise many of the problems related to neoliberalism's influence/control of CBT and, alternatively, the possibilities of CBT if properly facilitated: 'Current models of CBEs focus on conservation and evidence a preference for partnerships, particularly those involving white investors, and they do not adequately address the priorities of local communities. This therefore reinforces a neocolonial model, whereby control of tourism resources is vested in the hands of a few foreigners. CBEs are not perceived to have made a significant impact on poverty reduction at an individual household level. The current model of CBEs relies heavily on donor funding, thereby reinforcing dependency - an indicator of poverty [...] thus, the current model of community tourism development in Kenya requires urgent fundamental review [...]. If CBE initiatives were able to emphasise independence, address local community priorities, enhance community empowerment and transparency, discourage elitism, promote effective community leadership and develop community capacity to operate their own enterprises efficiently, then the impacts of CBEs on economic development and poverty reduction would be greatly enhanced' (Manyara \& Jones, 2007642).

\section{CBT characteristics and pre-conditions}

Recognising the present influence/control of neoliberal globalisation on CBT should not avoid proposing other various intrinsic characteristics and challenges that CBT has in its original conceptualisation. As such, some of the major characteristics of CBT are:

- Should be an indigenous effort; however, often long-term 'temporary' external support and facilitation (not participation) are necessary (Fernandes, 2011:1021; Giampiccoli \& Mtapuri, 2012; Mtapuri \& Giampiccoli, 2013);

- Should be based on local culture (Giampiccoli \& Hayward Kalis, 2012a);

- Should be seen, especially in its initial stages, as a complementary activity within the context of the diversification of livelihood strategies (Giampiccoli \& Hayward Kalis, 2012b; Nelson, 2003; Pérez, Barrera, Peláez, \& Lorío, 2010; Zapata, et al., 2011). Although due care should be taken, there should be nothing to prevent CBT becoming the main activity in a household if the opportunity arises.

- Should be aimed at individual and community-wide well-being, including direct and indirect beneficiaries (Ndlovu \& Rogerson, 2004; Singh, 2008; Suansri, 2003; Suryia, n.d.,);

- Should be considered a long-term approach to development and not a 'quick-fix' solution (Asker, et al., 2010; Hamzah \& Khalifah, 2009; Victurine, 2000; Wearing \& Macdonalds, 2002);

- Should prioritise and focus on training in a way that promotes skill/education in tourism with a spin-off in other community development matters - CBT's capacity-building should be a 'training ground' (Hamzah \& Khalifah, 2009) for general individual and community development matters (Hainsworth, 2009; Twining-Ward, 2007).

At the same time, the presence of specific preconditions can enhance CBT's success and potential. Therefore, pre-conditions such as the presence of natural attractions of interest to various specialist or general publics, as well as a local community that is well organised and aware of CBT and of its negative and positive impacts can have an enhancing positive effect on the CBT development process (Calanog et al., 2012; Denman, 2001).

Similarly, some of the usually recognised major challenges and problems in CBT development are:

- Marketing/market access (Denman, 2001; Forstner, 2004; Hayle, n.d.);

- Low community financial resources (Calanog et al., 2012; Denman, 2001);

- Low local capacity; therefore, the need for capacity-building (Aref \& Redzuan, 2009; Calanog et al., 2012; Manyara \& Jones 2007; Suansri, 2003);

- Lack of infrastructure (Nyaupane et al., 2006). This could be particularly true in the more remote areas; and

- The need to properly understand the term 'community', recognising that community does not refer to homogeneous entities, but 
represents the internal imbalance and heterogeneity of characteristics (Giampiccoli \& Haywards Kalis, 2012a; Lukhele \& Mearns, 2013);

- Economic viability (Goodwin \& Santilli, 2009).

Other proposed problems and limitations associated to CBT as a tools of development cooperation and poverty reduction, has been identified such as in increasing social differentiation and social unrest; problems with local decision-making, lack of local tourism business understanding and training, pseudoparticipation (Gascón, 2013).

\section{Issues of control and role of external actors in CBT}

The above argument leads to the proposition that the core of the matters in CBT is, therefore, related to issues of control. As such, Telfer and Sharpley (2008:115) suggest that it is fundamental to consider 'who controls community-based tourism and whether the benefits from tourism go to the local people or whether they are controlled by the local elite or external tourism development agents exploiting the local community'.

CBT must be recognised for its proper social justice and redistributive perspective linked to the alternative development approach. CBT, therefore, is anchored in concepts of alternative development through issues such as selfreliance, empowerment and sustainability where ownership, level of involvement and distribution of benefits are the recurrent issues. In 1979, de Kadt (1979), while discussing the case of a cooperatively-run community guesthouse, relayed the difficulties of a community-based approach.

However, control remains the key and, as already noted, especially in indigenous communities, 'control is key in any discussion of development, and tourism is no exception to this rule. Whoever has the control can generally determine such critical factors as the scale, speed and nature of development (Butler \& Hinch, 1996). Johnson (2010) agrees with many of the above-mentioned issues and proposes that, unlike a top-down approach, CBT, 'emphasizes local input and control over the type, scale and intensity of tourism development', therefore, communities can manage tourism development based on their own priorities and requirements. Community cultural and natural resources are often the bases upon which community development is promoted. In this respect, López-Guzmán et al. (2011) argue that

the decision to exploit natural and cultural resources in order to draw up development policies should come from local communities themselves. Moreover, it is clear that two essential elements should be taken into consideration when measuring their impact: firstly, the level of involvement of the local community and the level of control it has over tourism; secondly, the number and type of tourists.

Again, within this context, CBT is a tourism development approach where 'tourism is managed and controlled by the community' (Leksakundilok \& Hirsch, 2008; see also Giampiccoli \& Nauright, 2010). At the same time, CBT development should not be associated with predominantly (or only) business matters, as it is a more holistically empowering approach. If the main focus of CBT is business, then CBT may be seen to 'alienate rather than benefit the local community. Therefore, CBT should not be seen as an end in itself, but as a means towards empowering poor communities to take control over their land and resources, to tap their potential and to acquire the skills necessary for their own development' (Lukhele \& Mearns, 2013).

A fundamental matter is that CBT inherently works to break the dependency framework and unequal structure of the tourism sector, and to promote social justice and redistributive measures (Timothy, 2002). CBT should therefore be understood as a strategy for disadvantaged communities, which seeks to work in favour of more equitable social power relations at different geographical levels by advocating a social justice perspective (Giampiccoli \& Hayward Kalis, 2012a; Jealous, 1998).

Major challenges in marketing/market access in CBT are nevertheless recognised (CBI, 2011; 
Denman, 2001; Leksakundilok \& Hirsch, 2008; Timothy, 2002). Therefore, the need for a possible partnership with an external entity is seen as desirable and, if properly established and managed, valuable. Therefore, external entities are not excluded tout court from a CBT development process, but external entities intervention and connection with CBT development should have its limits. In this sense, an external partnership with (an) external entity(ies) can be useful; for example, where 'partnership with the private sector will bring in the tourists while the community manage their own facilities and activities' (Amat Ramsa \& Mohd, 2004:587). While challenges are present, community members should be directly involved and they should manage their own marketing because, as previously explained, even if challenges are present, 'marketing remains a crucial leverage point where community members can influence the balance between business and development goals. Participatory development and management define the integrity of CBT as a concept, but CBT marketing will decide the sustainability of CBT as a development tool' (Richards, 2005).

Similar to other matters related to CBT development, marketing/market access could need external facilitation. However, this should not be (nor become) associated with the perpetuation of dependency. Long-term yet 'temporary' facilitation/partnership processes should be implemented where the CBT members become autonomous and empowered sufficiently to be free to decide whether the continuing of the partnership is desired or not, instead of being forced to continue the partnership (and therefore dependency) to avoid the failure of the CBT project (Mtapuri \& Giampiccoli, 2013). External partner(s) involved should remain 'external'; that is, should not own or manage the CBT project itself, but should help externally (Mtapuri \& Giampiccoli, 2013). Empowerment should only be facilitated and not owned/controlled by external agents and its aim should be to make the local community not merely participate, but also to own and control (and be able to manage) tourism facilities and the development process. External control and paternalistic approaches do not work in favour of community empowerment and capacitybuilding, particularly where large companies are involved. A more positive approach is desired, such as, '[i]t is essential that good business mentoring is provided to the indigenous owners so that they can eventually manage their own enterprise effectively' (Scheyvens \& Russell, 2010).

It is important in a facilitative approach that external entities should not be included in the CBT venture itself (Giampiccoli \& Mtapuri, 2012). A facilitative approach that favours community ownership and management of the CBT ventures has been recognised to decrease future problems within the CBT project (Amat Ramsa \& Mohd, 2004). Although unlikely and improbable to occur with no external support or facilitation, CBT should be an endogenous endeavour (lorio \& Corsale, 2014; Mtapuri \& Giampiccoli, 2013). Zapata et al. (2011:22) follow very similar lines of thought when suggesting, 'The attention and resources of donors, policy-makers, and NGOs should be then better directed to support and stimulate the conditions for a local and endogenous development by providing the necessary resources (e.g. access to money through microcredit, land, ideas, contacts, ownership, influence, knowledge, skills) for the poor to take advantage of through local entrepreneurship, to develop and market products, and make linkages with local supply chains.'

It is a facilitative approach that can favour endogenous development for 'the only forms of local participation that are likely to break existing patterns of power and unequal development are those which originate from within the local communities themselves' (Mitchell \& Eagles, 2001; Mowforth \& Munt, 1998). Ultimately, 'people cannot be developed; they can only develop themselves' (Nyerere, 1976).

This section reviewed issues related to CBT's origins, definitions, theory as well as the practice of $\mathrm{CBT}$, the various characteristics and pre-conditions of CBT, issues on the control of CBT development, and the role of external actors. CBT's relationship with (and role in) community development within neoliberalism has been the main proposed argument. The 
next section will cover similar topics, but in relation to PPT.

\section{Pro-poor tourism (PPT)}

This section addresses the third objective proposed above and it puts forward the historical background of PPT. In addition, it advances a connection between CBT and neoliberalism, also proposing the inclusion of CBT within the PPT framework in the current neoliberal milieu. Always keeping in mind the neoliberal milieu, this section also proposes issues of control for the PPT process, PPT approaches in relation to community development with some brief examples, and PPT's underlying strategies. Finally, the section proposes a reflection on the role of PPT in wealth and resource concentration in the tourism sector and society.

\section{PPT's historical background}

PPT's origin can be traced back to the work of the UK's Department of International Development (DFID) who 'together with the Department for Environment, Transport and the Regions (DETR), commissioned a paper to be written on Sustainable Tourism and Poverty Elimination' (Scheyvens, 2007). The DFID seems very much within the neoliberal context that takes a private sector perspective and approach on how to decrease poverty and promote community development. As such, the DFID is not in search of alternative development approaches. Instead, the 'DFID is committed to maximising the contribution the private sector can make towards its poverty reduction goals through encouraging responsible business practices' and it advanced the concept of PPT (Goodwin, Spenceley, \& Maynard, no date). This approach to PPT development was developed in the late 1990s (Harrison, 2008). Its origin can also be correlated to the shift in the development sector as the 'development industry's move in the 1990s to establish poverty alleviation as the number one development agenda' (Scheyvens, 2007). It is worth recalling that (seemingly not coincidentally) it is exactly in the 1990s that the CBT lost its 'transformative intent of community development and does not focus on community empowerment' (Beeton, 2006). Within this context, it is not surprising that the PPT approach 'has been adopted by key tourism and donor organisations such as the UN World Tourism Organization (UNWTO), the UK-based Overseas Development Institute (ODI), the SNV Netherlands Development Organization (SNV) and the Asian Development Bank' (van der Duim, 2008; Scheyvens, 2007) and some specific organisations shifted their approach from CBT to PPT.

\section{PPT, neoliberalism and CBT}

As a consequence of the above mentioned, CBT has been inserted/circumscribed within the PPT approach. Therefore, a collaborative manual of the SNV and University of Hawaii, commissioned by the pro-poor tourism network 1 (Wehkamp, 2007), while presenting various 'usual' characteristics of CBT, seemingly proposes that CBT remains a sub-group of PPT. The document explains the two concepts as follows (Twining-Ward, 2007:9): 'Pro-poor tourism (PPT) is a new approach to the planning and management of tourism that puts those people living in poverty at the top of the agenda [...] Community-based tourism (CBT) is a type of sustainable tourism that promotes pro-poor strategies in a community setting.' Along similar lines, Goodwin (2006) mentions that 'Community-based tourism was a popular intervention during the 'ecotourism' boom of the 1990s. It is now being suggested as a form of pro-poor tourism.'

The insertion of CBT within the PPT milieu therefore seems a de-radicalising and moving away from more alternative development strategies and, instead, working towards the alignment of CBT with neoliberal strategies that validate and sustain PPT approaches. It should be noted here that the SNV is part of a group of key tourism donors who have now adopted PPT strategies in the tourism and development approach (see Wehkamp, 2007). That is, SNV has shifted its approach from CBT to PPT proposing attention on mainstream tourism instead of CBT (van der Duim, 2008). Some specific passage from a SNV document clearly describe the shift of SNV from CBT to PPT (and/or the inclusion of CBT within a PPT understanding), and as such the document titled Pro-poor perspectives in the tourism sector in Rwanda. Capitalization of SNV's Capacity Development Services 2005-2011 
mentions at different stages the changes/shift from CBT and PPT (to note that a specific section is title Shift to pro-poor mainstream tourism thus formalizing the change direction from CBT to PPT (see SNV, 2011:13). Specifically the document (SNV, 2011: proposes that "A pro-poor approach is at the heart of all SNV's capacity development activities and this could also add value to tourism in Rwanda. The objective of poverty alleviation led to the choice to support community based tourism and later the propoor mainstream tourism" (SNV, 2011:7 see also page 13).

Take note that the link (or thin line of separation) between CBT and PPT has been also proposed from the angle of tourism development model by international and national institutions (see Navas-Camargo \& Zwerg-Villegas, 2014:252). These institutions approach to tourism development "has given community-based tourism a high dependency on external donor funding. Furthermore, this method does little to empower the local communities; instead it often becomes an imbroglio of detachment and involvement, of paternalistic protection and mutual exploitation, of generosity and hospitality, and also of corruption and self-interest" (Navas-Camargo \& Zwerg-Villegas, 2014:252). In this context it has been added that distinction between CBT and PPT are minimal, thus "current CBT is only separated from "pro poor" tourism by a very thin line. Both of them, by definition, are developed in the heart of a vulnerable community which finds in tourism an opportunity to generate development. These two concepts of tourism are considered as vacation options for those seeking new experiences and for those who seek philanthropic recreation. By definition, pro-poor tourism needs the community to stay poor in order to be attractive (Navas-Camargo \& Zwerg-Villegas, 2014:252). Instead, if differently managed, a CBT can have its own success. Therefore, a reported case from Papua New Guinea that present specific characteristics such as 'the external assistance provided was purely advisory and facilitative; did not involve direct or indirect financial assistance; and non-financial assistance was provided only after a request from the landowner' that facilitate an approach of CBT that 'contrasts to the usual ENGO approach which is often based on external intervention and in many cases is designed to encourage conservation by promoting tourism development with economic incentives for participation' (Sakata \& Prideaux, 2013:881). This last CBT project in Papua New Guinea in its early stage is seen as a success (see Sakata \& Prideaux, 2013).

At the same time, concerning the UNWTO approach, it has been argued that 'despite the UNWTO's green and pro-poor agenda, it is basically following a neoliberal approach and its main aim is still to promote economic growth through tourism' (van der Duim, 2008). Within this context, it is relevant to highlight the 'propoor' concept genesis that 'has its roots in the modernization and neo-liberal theories in development studies, the essence of which was to infuse Western values and systems on the so-called 'Third World' countries' through specific discourse used and propagated by international institutions despite their distance from the real world (Jamieson \& Nadkarni, 2009). This beginning seems to be associated with the genesis of the concept of 'development'/'underdevelopment' - both based on Western ideologies (Adams, 2001).

Hegemony covers the political, economic and cultural areas. It must be understood within its international interstate system and class relation context, where the dominant ideology of a specific nation is able to spread its dominant hegemony through the world (Cox, 1996b; Bieler \& Morton, 2004; Cox, 1996a). It should be linked to issues related to discourse management (Foucault, 1972, Gosovic, 2000; Peet, 2002; 2003). Specific terminology is associated with the hegemony-discourse nexus, where discourse remains within specific limits and exploits specific terminology (excluding others) to construct a 'regime of truth' that becomes a Gramscian common sense (Foucault, 1972; Gosovic, 2000; Peet, 2002; Peet, 2003; Peet \& Watts, 1993). Within a current neoliberal context, Giampiccoli (2007:178) suggests that in 'the contemporary world, the existence of economic and political divergence together with cultural convergence is closely linked to the globalisation process 
and to Gramsci's idea of hegemony. A linearconsequential, but historical-geographic and flexible connection can be drawn between these three arguments'.

PPT remains within the global hegemonic discourse. It is suggested here that the terminology (and the term PPT itself) associated with PPT should also be seen as originating from and managed within, and to the advantage of, the neoliberal framework. In the end, it could be supported that 'supranational organisations have had difficulty coming to terms with and adapting their policies to the effect of increasing poverty and inequality beyond cosmetic alteration of names, titles and terms' (Mowforth \& Munt, 2003); the new (from the 1990s) term being PPT.

PPT research and practices can be seen as aligned with dominant thinking when arguing that PPT is embedded in and constructed by a specific discourse of development by proposing that PPT research might reveal, for example, how dominant ideas and practices related to tourism and development reflect a more general societal socio-political and socioeconomic discourse and developments. It might also disclose to what extent these ideas and practices are, for example, locked in to a linear thinking and to procedures and requirements (of for example, donors and wider public), such as 'the logical framework' and the 'impact assessments' (Van der Duim, 2008).

\section{Control of the PPT process}

A relevant issue is to examine who 'controls' PPT research and implementation. PPT is largely dominated by a small group of organisations and researchers (for example, UK-based Ashley, Goodwin, Meyer and Mitchell; South African-based Spenceley; and German-based Lengeveld) (van der Duim, 2008). Their reports are accessible on the Internet in specific websites (for example, ODI, SNV, Pro-poor Tourism Partnership), but 'hardly any are published in scientific journal' (van der Duim, 2008). In addition, because of resource constraint or lack of awareness of tourism potential by some institutions, much research is based on student or consultancy work, where ' $[\mathrm{t}$ ]he latter often reflects the needs of especially international development organization to 'prove' that they are effective' (van der Duim, 2008). Furthermore, van der Duim (2008) suggested that 'data to substantiate and strengthen PPT strategies are largely lacking'. The Pro-poor Tourism Annual Register (van der Duim, 2008:185) proposes that PPT impacts are still weakly demonstrable and are based on small-scale and or 'single product or locality'.

Despite these proposed shortcomings, it is worth noting that PPT has been seemingly seen as a 'TINA' and 'end of history' solution on the tourism approach to poverty alleviation; therefore, Mitchell (2010) proposes that: 'ODI now has a conceptual framework and a research method that has been 'battle tested' in about a dozen destinations in developing countries. It also has an accumulating evidence base that suggests that many assumptions about the impact of tourism on local communities are questionable. In fact, there is now a plausible case for advocating stronger linkages between mainstream tourism and PPT.'

It seems not coincidental that ODI presents itself as 'UK's leading independent think tank on international development and humanitarian issues' (in Mitchell \& Muckosy, 2008).

Within this context, it is worthwhile remembering Cox's (1996a) assertion that, '[t]heory is always for someone and for some purpose' (emphasis in original) and 'think-tank' policy debate is 'also aligned with the interests of political and economic elites' (Stone, 2000). It has been recognised that the 'imbalance of prestige, of intellectual authority, of financial weight and autonomy between the Western democracies and the rest of the world is reflected in the patterns of think tank development and the flow of the ideas through them' (Wallace, 2004). Think-tanks are 'embedded in the corporate, financial, trading, and developer worlds do not necessarily conspire as a class, and while there may be frequent tensions between them, they nevertheless possess a certain accordance of interests that generally recognizes the advantages (and now some dangers) to be derived from neo-liberalization' (Harvey, 2007). Through specific organisations such as the 
World Economic Forum, think-tanks exercise immense power (Harvey, 2007) and 'there is overwhelming evidence for massive interventions on the part of business elites and financial interests in the production of ideas and ideologies: through investment in thinktanks, in the training of technocrats and in the command of the media' (Harvey, 2007).

\section{PPT approaches and community development}

PPT has been quickly linked with the concepts of 'value chain' and 'pro-poor income'. Arguing against CBT, the origin, reasons and aims of the 'pro-poor value chain' approach are clearly mentioned by Mitchell and Ashley (2009) and need to be properly quoted in full: 'Developing countries are littered with well-intentioned community-based tourism projects, delivering small benefits to few people. Developed in isolation from commercial distribution channels, they lack the client volumes needed for commercial sustainability. In contrast, Ministries of Tourism and mainstream businesses often see increased arrival numbers as the barometer of success. Research by ODI suggests that neither approach is right, but tourism markets can - in some cases - be exploited for the benefit of the poor. The 'pro-poor value chain' approach to tourism has been developed by ODI, the International Finance Corporation (IFC), and the Netherlands Development Organisation (SNV), as a way to shift thinking from projects to interventions that harness markets and deliver impact at scale. By 'value chain', we mean the full range of activities that are required to bring a tourist to a destination and provide all the necessary services (accommodation, catering, retail, excursions, etc.). The approach 'follows the dollar' focuses on key points along the chain where interventions could expand income opportunities for the poor, within a commercial service sector. 'Pro poor income' (PPI) is the wages and profits earned by poor households across all the inter-related strands of the value chain. The aim is to support market-based interventions by analysing how poor target groups currently engage, how their positions can be upgraded and how changes in value chain performance would affect them.'
Notably, research adopting value chain analysis to the tourism system is growing (Rogerson \& Visser, 2011). Mitchell and Ashely (2010) recognise that there is the need to be cautious of the assumption that tourism development inevitably benefits them [the poor]' as under specific conditions fast growth can be harmful to the poor. Research by Saayman et al. (2012) focussing on South Africa seems to strengthen the argument that growth in tourism will, in reality, unfortunately penalise the poor and that specific circumstances have to be taken into account. Curiously Mitchell and Ashley (2010:24) acknowledge this when mentioning that studies 'have shown that, in addition to the environmental, social and cultural costs, often recognized in the research literature, an inbound tourism boom can, under specific conditions, generate economic costs. At times, these costs could be so significant that they result in the immiserisation of the host community'.

Specific perspective in relation to issues of reduction poverty is suggested by Mitchell and Ashley (2009): 'Sometimes international tourism is an effective way to transfer funds from rich tourists to poor people at destinations where, for every $\$ 4$ spent by a tourist, $\$ 1$ reaches the poor. Sometimes it is not. A comparison of results tells us about the propoor relevance of different market segments, direct employment in the sector, and about inter-sectorial linkages [...] this value chain approach to tourism is part of a wider shift in thinking. It shares objectives for sustainable poverty reduction at scale with those who use other approaches, such as Making Markets Work for the Poor. It goes beyond conventional supply chain analysis (of a single firm and its relationships) by taking an entire sector as the unit of analysis, including external institutions and a diversity of firms and strands.'

However, fundamentally, the sentence 'Sometimes international tourism is an effective way to transfer funds from rich tourists to poor people at destinations where, for every $\$ 4$ spent by a tourist, $\$ 1$ reaches the poor (Mitchell \& Ashley, 2009) seems very much in favour of the increase in the inequality gap and in reality 'it is an effective way to transfer' more 
funds to the non-poor, given that three out of four dollars go to them (and only one dollar out of the four to the poor).

An example proposed by Mitchell and Ashley (2009) in tourism-food supply link mentions that: '[t]he food supply chain to the tourist sector may be an important source of pro-poor impact. Such potential is realised in countries like Ethiopia (see figure 1), with few imports and a diversified agricultural sector, dominated by small-holders who receive a high percentage of the prices hotels pay for food [...] over $\$ 7$ million, or around $13 \%$, of the $\$ 55$ million spent by tourists on food and beverages reaches resource-poor food producers.'

As before, proportionally, much greater benefits are bestowed upon the non-poor, thereby increasing the inequality gap. In this case, $13 \%$ is seen as a success story! The general figure for the impact of tourist expenditure on the poor is $17 \%$ (Mitchell \& Ashley, 2009). If $17 \%$ goes to the poor, the remaining $83 \%$ may be supposed to go to the non-poor, thereby increasing disparities. Therefore, a pro-poor figure of $17 \%$ sheds some doubt on the success of the story and could hide the bias of equating growth with development. In line with this issue, it has been argued that Value Chain Approaches (VCAs) 'have quantified and demonstrated a point that has long been recognized in pro-poor tourism: what tourists spend, and how much they spend it, really matters' (Mitchell \& Ashley, 2010:134).

PPT advocates propose that 'the question of shares of benefits reaching the poor does not have to be isolated from issues of growth of the overall sector. [Value chain approach] has been used to answer questions both about how to increase the size of the tourism sector and also how to distribute its benefits more progressively. The logic of this approach also cautions against trying to establish an 'alternative' type of tourism that will benefit the poor - but rather to focus on the barriers preventing the poor from being beneficiaries of the mainstream tourism sector. As such, propoor [value chain approach] is a direct challenge to the remarkably dated view, still influential in parts of the tourism and development literature, that poverty reduction is most effectively achieved through the pursuit of equity rather than growth' (Mitchell \&Ashley, 2010).

Numerical matters are one side of the story; therefore, according to Binns (2002:79): 'economic growth [...] did not necessarily eliminate poverty and that the so-called 'trickledown' effects of growth generally failed to benefit the poor either in spatial or social terms [...] 'growth without development' was the result' ${ }^{2}$. It must be acknowledged that PPT 'recognises that the non-poor may also benefit from tourism, even disproportionately. It is less concerned with the relative than the absolute (net) benefits received by the poor' (Harrison, 2008:856). Therefore, the PPT approach needs to be verified within the assumption proposed by Britton (1981:19): 'the emphasis here, however, is not whether tourism is economically advantageous in aggregate terms, but to whom do these advantages accrue'. Britton's (1981) argument is paramount. This fact can recall that which was expressed by Britton (Pearce, 1989:94) that, within a dependency framework of the tourism sector, it is stated that 'while all participants in the [tourism] industry hierarchy profit to a degree, the overall direction of capital accumulation is up the hierarchy'. Commenting on the proposed PPT strategies, Fennel (2006) proposes that 'the preceding benefits, impacts and strategies for reform highlight the many inequalities that exist between parties of the North and South. But these inequalities have remained steadfast for years, and are symptomatic of the politico-economic structure of the industry [...] In an attempt to provide a balanced appraisal of the significance of the pro-poor tourism platform, there is perhaps an element of paternalism on the part of industry and other stakeholder groups that may be seen as distasteful. Although the basic tenets of the pro-poor tourism platform are sound in principle, knowing what is good or right for tourism in the lesser developed countries, and instituting measures from the most developed countries, may seem to some to be patronizing.'

The above lines seem to indicate that PPT seems more directed to increase the gap of inequality and power instead of decreasing it 
and putting the 'poor' in PPT firmly within a paternalistic and controlling approach, framing a dependency framework of tourism development. It relates more to a 'trickle-up' strategy than to a 'trickle-down' strategy. Within a PPT approach, while some benefits can accrue to the poor, it is the proportional disparity between poor and non-poor benefits, together with the continuing dependency framework within which the poor are maintained, that must be remarked, opposed and shifted.

As such, it is important to contextualise (and consider) the VCA within the current power relation structure (van der Duim, 2008). A study specifically looking at 'whether value chain development creates rural employment and reduces poverty', using the agricultural sector, asserts that the value chain can have a positive impact on a limited number of actors and produce local economic development, 'but it will not automatically create large-scale rural employment' (Posthumus, 2007:213) while ul Haque (2004:17) focused on the unbalanced power structure in value chain in an agricultural product, specifically cocoa. At the same time, it must be recognised that the tourism value chain mostly benefits the corporate world and 'makes a mockery of many of these enclavedriven (and so-called pro-poor tourism) interventions in developing and underdeveloped economies' that are sometimes a consequence of neoliberal macroeconomic policies (Nadkarni, 2008). Therefore, along the value chain ' $[\mathrm{t}] \mathrm{he}$ distribution of value added and the appropriation of profit at each stage of the chain depend on the market structure, the rules governing commercial transactions, and the corporate relationships that develop at each level' (ul Haque, 2004:17).

In addition, a lack of capabilities is also present in the tourism value chain approach, where 'lack of tourism-specific knowledge on the part of both government and the NGO community results in the unfamiliarity of the tourism value chain which leads to the exclusion of rural populations in tourism development schemes' (Slocum \& Backman, 2011:295). It could be that this lack of expertise forces or contributes to the fostering of the dependency framework in 'expertise' relaying on external actors (Chok et al., 2007). At the same time, while it is recognised that some forms of external 'collaboration is clearly necessary, what is of concern are the uneven socioeconomic relations that govern such 'collaborations' within the context of tourism development in developing countries' and the fact that the Northern countries are still in dominant control of the tourism sector (Chok et al., 2007).

Another very good example of PPT has been proposed: 'One of the most successful pro-poor tourism projects reviewed by ODI has trained indigenous people to work in a large, mainstream resort in Brazil. Within 18 months, local people accounted for half of the resort's employees - up from $10 \%$ before the intervention - and an extra \$2 million is flowing into the local community each year on a sustainable basis' (Mitchell \& Muckosy, 2008:1). In this case, it seems that PPT is related to employment. As much as an increase in employment of local people should be positively considered, it does not nurture the change/restructuring of the tourism sector itself.

The quality of jobs created should be also be considered (ILO, 2001); therefore, 'instead of aiming at job creation, pro-poor policies should focus on income and working conditions (Gartner \& Cukier, 2012:558). Specifically, when dealing with poor people, attention has to be paid to understanding the practical and moral matters in relation to job quality and payment. For example, in relation to wage, Chambers (1983) goes to the heart of the matter by stating: 'the basic belief that poorer people are, the less they should be paid. It is important here to distinguish the factual statement, that the poorer people are the less they are paid, from this moral statement, that poorer people are the less they should be paid. The factual statement is true; but when the objective is to reduce poverty, the moral statement is starkly perverse, since the more poor people are paid, the less poor they become. To say that poor people should be paid less is to say that they should stay poor. Yet whatever private and public views are expressed about reducing and eliminating poverty, the perversity persists. It is almost universal. Women are paid less than men; the 
disabled receive less than the able-bodied; the illiterate get less than the educated.'

Therefore, it is important to verify not only the quantity but also the quality and levels of jobs that accrue to the poor. Very importantly, however, it has been observed that even when proper regulation on minimum wage is followed to favour the PPT approach, there is no guarantee of the proper impact on poverty reduction (Gartner \& Cukier, 2012).

However, it has to be said that it has been acknowledged that PPT should be seen differently and be beyond the 'trickle down' effect (Roe, 2006). While the liberals and neoliberals focus their approach on the trickledown effect through which the poor should benefit, 'contemporary PPT approaches aim to establish a direct link between tourism and poverty alleviation and emphasise the voice and needs of the poor in tourism development' (van der Duim, 2008:183). Therefore, PPT is referred to as 'interventions within the tourism sector that focus on addressing poverty and move beyond 'trickledown' effects to generate net benefits to the poor' (Jamieson \& Nadkarni, 2009:116). In reality, instead, it seems that understandings of PPT still remain associated with the 'trickle down' effect milieu. In fact, for example, '[w]hile PPT initiatives must conform to certain government regulations (for example, paying for camping fees to the parks authorities in Masai Mara National Park) and tour operators have little influence on how the authorities reallocate their funds, the poor may benefit from tourism by being paid directly for their services and by increasing local sourcing, even though the state or authorities do not act as intermediaries responsible for a 'trickle down' effect)' (Cattarinich, 2001:71).

Marx (2011), examining the difference between CBT and PPT, explicitly links PPT with the 'trickle down' effect and market-oriented approach when she (Marx, 2011:22) mentions 'the notion of pro-poor tourism emerged with a more market-led approach [in comparison with $\mathrm{CBT}$ ] enabling more poor people to participate more effectively in the product. In straightforward terms, pro-poor tourism is not a niche tourism sector nor a specific product; it is a set of strategies whose aim is to have the benefits of tourism trickle down to vulnerable and poor communities, thereby enhancing links between tourism business and poor people, and thus to contribute to the poverty reduction development process.'

The market-failure proposition demonstrates that large parts of the population are excluded from the benefits coming from advanced economies and a value chain analysis narrates why 'producers in LDCs that were actually integrated were being pauperized nevertheless' as the trickle-down proposals did not recognise the power structures that impeded the ability of the weak node of the network to 'improve their relative positions vis-à-vis the strong' (Kalb, 2005:185).

\section{PPT underlying strategies}

PPT strategies are not legally enforceable, but rely on the goodwill of the tourism sector. Within this context, 'corporate social responsibility (CSR) and codes of conduct constitutes the ultimate neoliberal 'pro-poor tourism' strategy [where] governments refrain completely from interfering with market forces in order to stimulate 'growth for poverty alleviation' hence shifting responsibility for being 'pro-poor' to the private sector' (Schilcher, 2007:69). Currently, the private sector is seen as a central protagonist in shaping the policy and regulation: 'Improvements made by development agencies and governments to the enabling environment for tourism are more likely to be effective if the private sector is involved in identifying problems and articulating solutions' (Mitchell, 2010:6). Contradictions and gaps between theory and practice of code of conduct and selfregulation are, nevertheless, present and can ironically be more private sector friendly than pro-poor friendly (Scheyvens, 2007). In South Africa, for example, community involvement in tourism by private sectors seems to be more connected to 'public relation value' than real commitment to the contribution to community rights and development (Scheyvens, 2002). It seems that large tourism corporations' 'reputation' is the real issue at stake, not the wellbeing of poor people who become just a means towards the image-cleaning processes of private companies to regain and/or increase customers. These issues become evident when 
arguing that, "[s]everal outbound tour operators and hotel chains have a market capitalisation of EUR 2-4 billion, subjecting them to onerous review and reporting responsibilities. Corporate management is aware of the impact of negative stories emerging from developing country destinations. In this context, PPT initiatives can play a strategic role in reducing reputational risk. As tourist companies work in complex environments, they appreciate that positive socio-economic benefits can increase their 'social license to operate' (Mitchell, 2010:4).

Self-regulation does not guarantee the adoption of good practices by industry (Williams \& Montanari, 1999) and when supported by specific entities, such as WTTC and UNWTO, can promote profit-oriented strategies (Mowforth \& Munt 1998). Government intervention is, instead, seen necessary as '[e]ffective management systems for sustainable tourism are, however, likely to require intervention and regulation by the state' also based on compulsory regulation to avoid that 'some companies may gain competitive advantage by non-compliance with environmental standards' (Bramwell \& Lane, 2010:1).

\section{PPT and wealth and resource concentration} In the end, it is possible to agree that PPT 'is another form of neoliberalism that fails to address the structural reasons for the northsouth divide, as well as internal divides within developing countries' (Hall, 2007:4). The association of PPT strategies with neoliberalism seems complete when producing a tourism context where the poor remain in a dependency framework and/or they lose (the inequality gap increases). Therefore, as mentioned by Schilcher (2007), issues of proportional redistributions and code of conduct all work in favour of controlling actors of the neoliberal hegemonic system where pro-poor policies increase inequality instead of decreasing it. To such end, instead, '[u]ncompromising pro-poor tourism implying that 'the poor' reap un-proportionately higher benefits than 'the rich' would necessarily take the form of local ownership and compulsory local sourcing in an environment where the poor' have been granted access to the assets of land, credit and skills' (Schilcher, 2007:71).
However, the neoliberal milieu militates against this goals and '[r]egulation and distributive strategies are virtually prevented not only through ideas - in a Gramscian sense the hegemony of a neoliberal ideology - but also institutions' (Schilcher, 2007:71). Within this context, the fostering of social equity remains outside the advocates of PPT, working in line with neoliberal and tourism and travel industry and will recognise that a 'soft' approach to PPT 'involving self-regulation -such as voluntary codes of conduct -will be sufficient. However, this is most likely to result in relatively small direct benefits for the poor while continuing with growth ethos that maximizes benefits to the non-poor' (Scheyvens, 2011:221).

Unequal control and benefits of the tourism industry are increasing concentration in the industry. For some time, it has been suggested that the tourist accommodation sector has demonstrated increased market concentration by a few large corporations. Primarily through horizontal integration, a handful of TNCs have emerged as powerful oligopolies' (loannides, 1995:52). More recently, Wood (2009) also mentions that concentration is increasing, especially throughout the 1990s, especially after the GATS became effective. For example, the world's major airlines have 'coalesced into a handful of mega-alliances' (Bellamy Foster, McChesney, \& Jamil, 2011).

Within this context, the investigation between tourism, community development and the neoliberal framework has already been proposed and it has been suggested by Schilcher (2007) that: 'opportunities for 'the poor' themselves to participate in the tourism industry, for example, in the form of community tourism enterprises or small-scale locally owned business, are weakened in a neoliberal environment due to competition from capital-intensive, verticallyintegrated MNEs [Multinational Enterprises], or due to market entry constrains given 'the poor' limited bargain power and access to assets such as capital and land [often] without any protective intervention by the state.'

The spreading of neoliberal forces and the inclusion of poor people within the mainstream tourism increase their dependency possibilities and the inequality gap, in addition to losing 
specific cultural context reshaped by the mainstream Western ideology. On this last issue, a case from Thailand noted that 'within the last two decades, the influence of liberalcapitalist politics at the lowest community level has changed perceptions of the leaders. The benefits of new business, including tourism, have encouraged some leaders to use their position of power to gain individual economic advantage, thereby undermining community initiative' (Leksakundilok \& Hirsch, 2008:214).

Moreover, external forces, thanks to their greater human and capital resources, can, in the quest for profit, side-line local actors. Through the mechanisms of concentration and market dominance, large companies are at the forefront of this process. This state of affairs seems very much in support of the continuous rise of concentration of capital in few giant tourism corporations opposite to local more diversified structure. Therefore, '[i]n the context of regional development it is important to note that while initial control of the industry is held locally, eventually larger multinational firms enter the market' (Telfer, 2002:123).

It is interesting to note that it has been suggested that PPT does 'apply to any kind or type of tourism, including large- and smallscale tourism, even if the non-poor also benefit. Can be from regional or national policies or private sector involvement [...] Mass tourism, even in its most extreme forms, can potentially be considered a form of [pro-poor tourism]' (Harrison, 2008:856). Mitchell (2010:4) confirms this matter by writing that 'any type of tourism can be pro-poor'. Within this context, tourism can serve very much to the expansion of capitalism (Bianchi 2009; Bianchi, 2010; Giampiccoli, 2007; Lefebvre, 2002). Tourism and international cooperation to favour poor community development within this perspective can serve as an instrument of capitalist penetration in 'virgin' territories and fit well with tourism organisations and private capital that use the pro-poor tourism label to sell 'tourism under the banner of poverty alleviation, coupled with the fact that tourism fits with donors' neoliberal approach to poverty alleviation based on economic liberalization and private-sector driven growth' (Schilcher, 2007:63). Therefore, 'organisations that need more tourism are bound to emphasise tourism's pro-poor potential to donors while promoting neoliberal approaches in which the industry can flourish' (Schilcher, 2007:64).

This section exposes the historical background and advances the relationship between PPT and neoliberalism. Moreover, issues of PPT approaches, in relation to community development and PPT strategies and their role in concentration of wealth and resources, have been proposed.

\section{CBT specificities}

The section covers the fourth objective of this paper and it reviews the specificities of CBT based on matters raised from a PPT-friendly perspective. The following issues are reviewed: scale of impact, collective entrepreneurship and implementation approach. The last two matters should be seen interwoven with each other.

\section{Scale of impact}

Mitchell and Muckosy (2008:2) argue that '[m]any community-based tourist initiatives are ineffective at reducing poverty at scale'; therefore, the need is to establish a stronger link with mainstream tourism sector to increase the positive impact on the poor. Similar thought in relation to the scale of impact of CBT is presented again in another document on PPT mentioning that '[d]eveloping countries are littered with well-intentioned community-based tourism projects, delivering small benefits to few people' (Mitchell \& Ashley, 2009:1). Certainly, the matter related to scale is paramount as it is only through appropriate scale of impact that a valuable reduction of poverty and community development can be satisfactory (keeping in mind, however, that economic impact is only one side of the story and benefits can accrue also in other guises, such as increased capacity/skills, various forms of empowerment, etc.).

Small-scale projects in tourism should not be abandoned, and certainly CBT is usually understood and practised within a small-scale development strategy (especially in its initial stages and possibly also because of communities' - especially poor communities limited resources). However, at the same time, 
effort should be made to scale-up CBT concepts and practices to have greater impact. There is no conceptual or practical restriction to the scale-up of CBT development. Effective global restructuring of the tourism system cannot be on small scale. In the case of tourism, the aim should be work toward a 'mass CBT' that is working towards mainstreaming CBT concepts and associated practices (Hamzah \& Khalifah, 2009). Therefore, while it has to be acknowledged that 'CBT is generally small scale' (Asker et al., 2010), especially in its first stage(s), its greater scale should be seen as not precluded or intrinsically not considered possible. CBT should not be seen restricted to small impact understanding but, even if this should be difficult, CBT ventures should strive and be understood, conceptualised and implemented to have an ever-increasing scale of impact.

CBT relies on the establishment of communitybased enterprises (CBEs) (see Calanog et al., 2012; Manyara \& Jones, 2007), where a tourism CBE can be defined as a 'sustainable, community-owned and community-based tourism initiative that enhances conservation and in which the local community is fully involved throughout its development and management and is the main beneficiaries through community development' (Manyara \& Jones, 2007:637). In disadvantaged community settings, often constraints are present to allow the increase in the scale of action. Within this context of constraints, it has also been noted that community initiatives often need to compete with public and private initiatives and housing, transport, and tour management (the larger revenue maker in tourism), but lodging is 'perhaps the simplest of these components for communities to provide, and it may range from local home stays to luxury accommodation' even if capital constrain make difficult for community alone to enter the luxury market (Turner, 2006). Therefore, there is the possibility of action here to start to enter the mainstream tourism within a CBT approach.

Stating that CBT can be seen as a 'type of tourism run by and for the local community' it has been proposed that CBT 'can be alternative in character like the Calamanco scheme in Senegal or may cater for larger numbers and have more in common with aspects of mass tourism' (France, 1997:16). Graphically, France (1997) shows how CBT can include mass tourism. Therefore, CBT can be scaled-up towards mainstreaming it.

A study of CBET in Ecuador proposes that 'CBE [community-based ecotourism] can and should benefit not only the immediate community, but also the regional, national and even global community' (Peaty, 2007:74). In a Tanzanian case study, Akunaay, Nelson, and Singleton (2003) indicate the need to diversify the tourism industry, enhancing CBT ventures, while linking diversification and macroeconomic growth. While suggesting that 'macroeconomic growth required to combat poverty will only happen if high potential sectors such as tourism lead the way' (Akunaay et al., 2003: 4), the same authors indicate that '[l]ocally controlled CBT activities are essential to link macroeconomic growth and investment in the tourism industry with rural economic opportunities and micro-level diversification (Akunaay et al., 2003:9). However, it needs to be emphasised that locally controlled tourism that could be seen as appropriate in CBT is not enough to be considered CBT, for CBT should be specifically intended for disadvantaged people. That is, the disadvantaged sector of society should be the one strongly prioritised in the control of (and to benefit from) CBT products and services.

It has to be recognised, however, that many CBTs run at low occupancy rates (Mitchell \& Muckosy, 2008). The complementarity to other activities makes CBT ventures more flexible and more able to work at this low capacity. Often, because of its complementary position, CBT is understood and judged in its success within a context of limited impact of community development, particularly from a monetary perspective. From the experiences of a Namibian case, where CBT was widely endorsed by government, the role of CBT should be understood, not from a national perspective of foreign exchange earnings, but on its local economic development potential. Therefore, while it 'does not contribute to the national economy in terms of foreign exchange [...] it does have local economic significance (Jänis, 2009:13). Complementing other 
economic sectors with CBT can reinforce success. Drumm (1998) compares the low occupancy levels of CBT operations in the Amazon region due to limited market access against their private sector counterparts and suggests that the community-based operations still enjoy an advantage, thereby implying that even a small income is very valuable within impoverished contexts.

Micro-and small enterprises are usually seen as the only possible type of CBT ventures. However, very recently, 'A manual on establishing Community-based Ecotourism Enterprise (CBEE) in the Philippines' (Calanog et al., 2012) also proposed that CBEs can operate at greater scale when CBE and microenterprise features were compared. The same manual (Calanog et al., 2012) also sees cooperatives as a possible CBE system (see Table 1).

In 1998, it was proposed that the proper facilitation and technical assistance of community-based sustainable tourism (CBST) were required to provide technical assistance related to the mechanics of running a tourismbased enterprise' to allow a CBST project 'to successfully compete for its share of the market if it is to become a sustainable enterprises model [...]. Communities should have the proper organisation and financial capability to operate on a limited scale or even full-blown commercial scale' (Jealous, 1998:12). In support of the scale-up of the impact of CBT, it has been properly argued for the APEC countries that, 'in the light of the growing importance of tourism as a tool for economic regeneration, it is imperative that the principles and mechanisms of CBT are mainstreamed [...] By doing so, CBT will no longer be an alternative development model but a formal development tool' (Hamzah \& Khalifah, 2009:2).

CBT should be interpreted within the context of growth working towards the restructuring of the tourism industry on a global scale, not as a 'paternalistic' niche segment of the tourism industry. The conclusions of a study on scalingup community-driven development (CDD) suggest that the presented examples of community-based development initiatives work to change the control of decision-making and resources in favour of communities (Gillespie, 2004). It has been proposed that although much CDD is usually small scale, its potential has not been yet demonstrated and although 'it is no longer true to say that CDD operates at the margins, it has yet to fully infiltrate the mainstream when large-scale programs are at stake. No matter how effective a scattering of small-scale initiatives are, the achievement of national and international goals, including the Millennium Development Goals, will not be possible without effective large-scale action' (Gillespie, 2004:2).

The same World Bank document proposed the need of scaling-up CDD where 'scaling up' is defined as seeking 'to reach the greatest possible number of poor people, and to

Table 1. Difference between CBE and micro-enterprise

\begin{tabular}{|c|c|c|}
\hline $\begin{array}{c}\text { Point of } \\
\text { comparison }\end{array}$ & $\begin{array}{c}\text { Community-based } \\
\text { enterprises }\end{array}$ & Micro-enterprises \\
\hline Size &  & $\begin{array}{ll}\text { - } & \text { often small scale } \\
\text { - } & \text { have fewer than } 10 \text { employees } \\
\text { - } & \text { vulnerable to competition } \\
& \text { under-capitalised, with less than } \\
\text { PhP 1M start-up capital }\end{array}$ \\
\hline $\begin{array}{l}\text { Generation } \\
\text { of jobs }\end{array}$ & $\begin{array}{l}\text { - can generate more jobs and return } \\
\text { benefit to the community beyond } \\
\text { those directly employed }\end{array}$ & - unable to generate more jobs \\
\hline $\begin{array}{l}\text { Owners I } \\
\text { Operators }\end{array}$ & $\begin{array}{l}\text { - can be operated as a worker-owned } \\
\text { cooperative or as a member-based } \\
\text { association } \\
\text { profits equitably distributed to } \\
\text { members/owners }\end{array}$ & $\begin{array}{ll}\text { - } & \text { usually owned by single } \\
\text { - } & \text { proprietorship or a family } \\
\text { profits are privately accumulated }\end{array}$ \\
\hline
\end{tabular}

Source: Adapted from Calanog et al. (2012:184) 
motivate and empower the greatest number of communities to take control of their own development' (Gillespie, 2004:2). Scaling-up CCD means to scale-up the empowerment strategy in its entirety and to 'empower communities and local governments with resources and the authority to use these flexibly, thus taking control of their development' (Binswanger \& Aiyar, 2003:5). The scaling-up of CBT should be seen in the same perspective, thereby leading a shift in the control of resources and decision-making processes towards communities, and to work towards a global change.

The scale level that CBT could (perhaps, should) achieve is very important when related to the general shift that CBT could contribute to the general rebalancing/redistribution of control, resources, knowledge, capacities and benefits of the tourism sector as a whole. CBT must not be seen as a small, somewhat marginal, tourism segment, but should strive to become the central/main tourism segment of the tourism industry in order to shift the control of the industry to local community members.

This CBT approach, instead of PPT strategies, should be mainstreamed and prioritised by government tourism strategies if proper poverty reduction and community development (associated with the decrease in inequality) at scale are to be achieved. At the same time, while CBT concepts and practices should strongly and unconditionally continue to prioritise and be specifically related to (and holistically benefit) disadvantaged communities' members within a redistributive and social justice framework at global and local level, it should also spin off to all tourism sectors. As such, CBT should work to localise the ownership and control of the tourism sector as a whole. While CBT must be much more proportionally directed to offer a strong and decisive advantage to disadvantaged communities' members (vis-à-vis more powerful/wealthy groups of society) and must strongly and holistically decrease the inequality gap between various groups of society at various geographical levels, it should influence and circumscribe the whole tourism sector (and society) to enhance the local control of, and local benefit from, tourism.

\section{Implementation approach and collective entrepreneurship}

It is important to investigate the implementation approach and the type of entrepreneurial model utilised in CBT projects, as it is how these features are understood and managed that can influence the outcome of the CBT itself. Within this context, collective entrepreneurship has been seen as jeopardising the outcome of CBT development. As such, Mitchell and Muckosy (2008) propose the weakness and inefficiency of collective enterprise mentioning that: 'Collective management structures are often too cumbersome and complex to work effectively. The imposition of democratic and secular institutional forms on communities with traditional patterns of authority can also have unintended effects. For instance, many CBT projects have a management committee and constitution that is fully inclusive and gendersensitive. In reality, however, it is often traditional authorities that dictate the critical decisions - particularly with respect to financial resources. CBT projects can have the unintended effect, therefore, of bolstering patriarchal power structures while muting further discussion on how to change them.'

In addition, Mitchell and Muckosy, (2008:1) argue that, '[i]n addition to being an inefficient business model, CBT is not participatory in many cases'.

\section{Implementation approach of CBT}

Based on the above, two points need to be considered; firstly, local culture is not static and should be the substratum on which to build CBT development; and secondly, the way the project is implemented can itself be the reason for improper development of the collective management system.

Community development is based on local culture. This local context should be seen as a starting point, that is, '[c]ommunity development with indigenous communities makes sense only if it is undertaken within indigenous cultural traditions' (Ife, 2002:183) where facilitators (the 'experts') value local knowledge, culture, resources, skills and process (Ife, 2002). Therefore, individual development must be seen, primarily, as development within the community where a 
'community-based approach to personal growth and development would seek to find ways in which people's individual needs can be met through community networks, structures and interactions, rather than through professionalised and packaged services' (Ife, 2002:195). However, very importantly, and to be kept in mind all the time when speaking of local culture/tradition, local culture must be appreciated and understood as an active protagonist, as a 'transformed and transformative force', and not as a stagnant obstacle (Escobar, 1995).

Local culture is not static, but evolves independently and with its own interactions with other external cultural milieus. Therefore, the 'CBE's governance structure is typically rooted in cultural traditions' and when, as Peredo and Chrisman (2006) state that as 'CBEs grow, more formal structural and administrative systems tend to emerge as needed. In CBEs, one can frequently recognize the coexistence of traditional ways of life, based on cooperation, alongside market-oriented processes. This is where socially adaptive innovation often takes place in the creation of a new organization. Members of CBEs typically regard the enterprise as a naturally evolved social and economic form, adapted to the realities and pressures of the market economy while integrating their own cultural traditions.'

This CBT process can be facilitated by the local cultural role in contributing to tourism control under parameters that are controlled and managed by the community for the community (Mitchell \& Reid, 2001).

The relationship process between local and external cultural milieus should be, very importantly, under full control and management by the local people, and not managed by outside actors. Properly, Wearing and Macdonalds (2002) suggest a paradox in CBT development in marginalised communities where, despite possible shifts in the tourism development approach by Western-based actors, the tourism model that communities know is only that of the Western-based model itself; however, changing conditions open new opportunities.
To achieve these opportunities, 'there is a need to change the balance between the dominant western values in tourism and their treatment of developing countries as 'other' in the development of community-based tourism' (Wearing \& Macdonalds, 2002:200). The same authors (Wearing \& Macdonalds, 2002) suggest a more participatory approach, drawn from Chambers (1983) such as 'Rapid Rural Appraisal' (RRA) and 'Participatory Rural Appraisal' (PRA). They (Wearing \& Macdonalds, 2002) continue by advising that the 'development agent and the tourism operator who enter into rural and isolated area communities have no real prior insight into rural and isolated area knowledge and the strategies of power that take place within this reality [...]. The development agent and tour operator require on-ground knowledge in order to be able deliver a successful development project.'

However, most development projects follow the standardised Western neoliberal approach where local realities are ignored, are seen as inferior/not useful, are overlooked, disregarded, misunderstood or seen as inappropriate. The approach of tourism policies in developing countries has been based on 'technocrats' models of tourism master planning [and] constituted one component amongst a cluster of tourism-related policies which aimed to promote a particular kind of tourism rooted in a Western economic rationality' (Bianchi 2002:273). 'The Rainforest Alliance, for instance, found that $40 \%$ of CBT projects in developing countries did not involve communities in decision-making' (Mitchell \& Muckosy, 2008). This should be investigated in relation to the implementation approach that these projects have followed.

These issues are valid for both the implementation process and for the evaluation account. Within this context, there is the undervaluation of collective management possibilities that could be historically in place. Issues of participation and collective management possibilities should also be considered in relation to a specific cultural context that might well be quite different from the 'Western-based' approach. Peredo and Chrisman (2006:311), in their study of CBEs as alternative development strategy in poor 
communities, note that 'international development agencies from industrial countries and multinational organizations have been heavily involved in interventions in the developing world over the past fifty years'. However, the results have been disappointing and remain within a paternalistic framework, ignoring local cultural context instead of facilitating selfreliance (Peredo \& Chrisman, 2006).

In the last decade, the recognition of problems, has, however, led international agencies to focus 'design projects with a view to increasing the participation of local beneficiaries' (Peredo \& Chrisman, 2006:311). Despite this change in approach, the results continue to offer challenges that make the real involvement of the beneficiaries difficult and often 'the creation of local institutions by outside agencies has weakened or replaced local conventions. Frequently, poor people participate in the novel institutions only as long as there are tangible rewards, such as food aid, to be gained. What may be called a 'beggar mentality' has thus emerged in many communities where there have been massive aid interventions' (Peredo \& Chrisman, 2006:311).

Peredo and Chrisman (2006), arguing on the disappointing achievement of international aid, go as far as to write that: 'Indeed, it has been demonstrated that the real effect of many developmental activities has been to compromise community support systems and to contribute to the creation of real poverty.'

CBT has to be implemented properly to enhance its chance of success. A Wild Coast project in South Africa supported by the European Union (EU) seems to show exactly the opposite. In general, the project has been proposed as top-down development (Kepe, Ntsebeza, \& Pithers, 2001). Lack of real participation in the implementation phase of the project (or programme) has been also advanced the 'lack of community ownership of the programme engendered in the conceptualization and design phase was further exacerbated in the programme implementation phase the by community's 'passive' participation [...] These participative processes reinforced the lack of community programme ownership, impacting on programme commitment as the community could not act on their ideas to guide programme relevance and associated capacitybuilding requirements' (Wright, 2005). ${ }^{3}$

As described for the initial locally-developed Amadiba CBT project (the project supposedly to be followed by the EU supported project), it was the local community that sought help when, in 1997, PondoCrop, a NGO working the area, 'was approached by the local people in Amadiba to assist with initiating a tourism development project' (Russell \& Kuiper, 2003:159). The private sector is not completely excluded, but has been involved depending on the project stage and, most importantly, under community decision (not vice versa, as the private sector that involved the community). This may be seen in the following example: 'Once the horse trail enterprise was set up and running, the local community wishes to explore additional tourism activities in the area and, with the help of PondoCROP, approached a private investor in 1998 to investigate the feasibility of a pilot catch/tag-and-release flyfishing operation in the area' (Russell \& Kuiper, 2003:156).

Thereafter, the EU-supported project opened new perspectives. In fact, the clash of approach and understandings in the project development has been properly exposed by the ECODES (2003): 'What has become apparent is that there are potentially conflicting development philosophies / ideologies being driven within the programme. On the one hand an approach to set up the community as full owners of all facets of a tourism project, that is, a wholly community driven approach that then involves private sector. On the other the approach outlined in the financing agreement that advocates the use of a private sector driven approach that ensures optimum community involvement.'

The opening of the new phase of the projects funded by the EU sought to shift the project's approach and philosophy. Very importantly, it did not work from indigenous needs and requirements, but from external requirements towards the more Western-based needs and concepts of efficiency, growth and management (Ntshona \& Lahiff, 2003). The 
limits of the parameter of intervention in CBT can be seen where, as much as, possible movement to a more participatory approach can be present; these remain within the limit of Western (implementer-facilitator) understanddings, practices and needs. It is elucidative to mention that it has also been recognised that, '[t]raditional methods of CBT planning have moved from top-down to participatory approaches but remain one-sided in that they encourage communities to understand Western notions of 'tourism and tourists' but do not encourage partners in CBT development to understand the community perspective' (Sammy, 2008:76).

It seems ironic that critics of CBT note that 'advocates for CBT in Latin America should acknowledge the shocking lack of financial viability for most CBT projects, or more are doomed to failure. And the collapse of a CBT project can be harrowing, often pushing poverty above pre-project levels. Consultants and donors can move on, but the supposed beneficiaries may have invested their own assets in tourism projects and abandoned alternative livelihoods' (Mitchell \& Muckosy, 2008).

Most likely, the implementer personnel of the Wild Coast project probably 'left the scene' and went to work elsewhere. As much as the local stakeholders should (must) take their own responsibilities and commitment, the burden of the possible failure of the project should not be attributed (as it is easy to do so) prejudicially to beneficiary community members. Nevertheless, in general, putting the failure of the project on local entities and the community remains the preferred strategy (see de Beer \& Marais, 2005; Pleumaron, 2002).

External facilitators can be the 'involuntary' originator of arising conflict because of the specific approach to a community project. One of the possible categories of internal community conflict arising from the flow of benefits from the commercial or other use of wild resources is the 'tension between traditional and democratic forms of community governance', but counter tendencies that also could re-establish a positive situation of collective governance and benefits (Koch,
2004). The intrusion of new revenue can greatly enhance the internal conflict over their control (for similar situations, see Leksakundilok \& Hirsch, 2008). At the same time, external entities, if properly trained, can sometimes come to help as community members become aware of the problems (Boggs, 2004) and Zapata et al. (2011) in relation to the role of the external facilitator in promoting community redistribution of benefits in CBT.

It is the implementation/management approach in CBT development that is paramount. Dixey (2005) mentions, trusts are increasingly being promoted as the preferred model for CBT development if considerable infrastructure is developed to ensure asset ownership and prevent interference from traditional chiefs. The trust model is also favoured as it can improve governance and transparency and enables business partnerships with the private sector.

However, the same of the general community development approach CBT should start from the local cultural context and fit into it during its development process; thereby, each community will have a different specific need to have (or not to have) specific organisational structures. In addition, the possible legal structure should incorporate measures of 'checks and balances' and transparency that allow and permit all community members who desire to actively participate in, and control the work of, the established legal entity to do so. The formalisation of specific institutional structures, such as trusts and cooperatives (if properly originated from, and embedded within, the local context and valued by the project participant), can also come to assist in facilitating a more equitable distribution of benefits and will be recognised as an important structure by the community itself. In a Thailand case study, a cooperative structure was locally formed and was recognised as necessary by the same community members (Jamieson \& Sunalai, 2009). The same CBT project have been seen as successful thanks to the proper external facilitation by local and national governments, by community receptivity of external advice and by 'committed and high quality leadership' (Jamieson \& Sunalai, 2009:93). Specifically, the cooperative structure 
'has turned out to be one of the most important tools for ensuring equitable distribution of tourism resources' (Jamieson \& Sunalai, 2009:93). Examples show that cooperatives can be instrumental in CBT development (Kontogeorgopoulos et al., 2014; Mielke, 2012; Mohamad \& Hamzah, 2012; Dichter \& Dall'Ara, n.d. in relation to the possible use of cooperative in the type of tourism system denominate 'Albergo Diffuso' - 'Scatter' or 'Spread' hotel).

\section{Collective entrepreneurship}

Arguing in favour of PPT and against CBT, Mitchell and Muckosy (2008:2) mention collective entrepreneurship as a major obstacle by stating, 'CBT is based on the notion that a sophisticated service sector, like tourism, is best managed by a large group of community members. The agricultural sector abandoned this idea after disastrous flirtations with collectivisation initiatives in the 1960s and 1970 s. The tourism sector has yet to fully learn these lessons'.

Peredo and Chrisman (2006:315) state: 'CBEs are owned, managed and governed by the people, rather than by government or some smaller group of individuals on behalf of the people. They are governed rather than govern.' In addition, they foster democracy, as in CBEs', '[g]overnance structures tend to be collective and management structures democratic' (Peredo \& Chrisman, 2006:321). The same authors (Peredo \& Chrisman, 2006:316) establish a fine line between CBEs and cooperatives and suggest that cooperatives are not necessarily CBEs. In their (Peredo \& Chrisman, 2006) words, '[c]ooperatives are not, in theory, CBEs either. The particular membership of cooperatives is marked by a shared interest in a cooperative activity, rather than a shared interest in a community that acts cooperatively, as is the case for CBE's [...]. In practice, some cooperatives identified with specific communities may be borderline cases. The world may not be perfectly tidy with respect to what is and what not a CBE is.'

At the same time, following similar lines Peredo and Chrisman (2006), it is here argued that cooperatives (as Peredo and Chrisman seem to keep an open option) can be interpreted as CBEs. Therefore, a cooperative

can function as a CBE because community members can have a shared interest in a venture and still act cooperatively toward community development. It can also be argued that community members can act cooperatively even without a venture. By extension, this article advances the notion that other specific forms of organization, whether legal (formal), such as non-profit organizations, or trusts, or customary (informal) such as a village community assembly or other forms of established customary organizations with some form of management and a properly recognizable structure and management procedures can be considered as CBEs (Mtapuri \& Giampiccoli, 2013).

At the same time, CBTs are usually 'exclusively' understood as a collective enterprise system. However, while that is the ideal characterisation of CBT, it must be noticed that in the same vein, CBT should encourage initiatives to develop other micro or small ventures that, once formed, should also join the umbrella organization' (Mtapuri \& Giampiccoli, 2013). Therefore, CBTs do not eliminate micro- and small companies that can also be favoured, as much as they remain within certain parameters belonging to CBT development (Mtapuri \& Giampiccoli, 2013).

Scheyvens (2002) notes that when based on local skills and resources, small-scale tourism can have a positive effect on people participation and empowerment. Additionally, small-scale tourism is recognised to have a more positive effect on wealth distribution, especially with governmental structure and support, and therefore on the reduction of economic leakages. As noted by Timothy (2002), small-scale tourism ventures have the potential to involve marginalised groups such as women, especially if they are based on local skills and resources and particularly in circumstances that allow for keen the participation and empowerment of communities. 
The collective management system can be used in many different scales and different contexts, and they have similar efficiencies to those normally conceived as belonging to private enterprises. Again, it should here be noted that, in 2011, research shows, '[w]orker cooperatives can be at least as efficient as privately owned, hierarchically managed firms' (Fields, 2011:83). Collective entrepreneurship systems such as cooperatives are invaluable. Repeating what has already been said: 'Despite [...] difficulties, the lesson from the cooperative movement is that cooperative structures are indeed feasible, in a wide variety of social, economic, political and cultural settings. The community-based alternative would most likely incorporate some if not all aspects of the cooperatives movement' (Ife, 2002:135).

Despite challenges, the cooperative system continues to inspire people and has 'endured and thrived in many countries of the world' (SAF, 2003:2). Unfortunately, the cooperative concept has suffered various inappropriate understandings and misunderstandings from various political perspectives. 'Yet, despite this, co-ops have remained predominantly associated with support for wider democratic ideals, with broadened forms of worker and community ownership, and with popular participation and community solidarity' (SAF, 2003:2).

It is worthwhile mentioning, in seeming contrast to what has been advanced by Mitchell and Muckosy (2008), that cooperatives, as a major collective management approach, are still seen positively by many quarters, also by the United Nations, which sees the cooperative as a valuable management system. For instance, 2012 has been declared The International Year of Co-operatives by the United Nations. On their official website (Coop, 2012a), it has been stated, '[c]o-operatives are a reminder to the international community that it is possible to pursue both economic viability and social responsibility.' Importantly, the International Year of Co-operatives by the United Nations 'is an acknowledgement by the international community that co-operatives drive the economy, respond to social change, are resilient to the global economic crisis and are serious, successful businesses creating jobs in all sectors' (Coop, 2012a). The relevance of the cooperative system is underlined by writing, '[t]he United Nations estimated in 1994 that the livelihood of nearly 3 billion people, or half of the world's population, was made secure by cooperative enterprise. These enterprises continue to play significant economic and social roles in their communities' (Coop, 2012b). Again in 2011, '[t]he cooperative entrepreneurship is now considered a model of community growth' (Tewari, 2011:8986). The role and potential of cooperative and social enterprises are often underestimated; however, 'they often achieve economic and social outcomes that are better than those achieved by conventional enterprises and public institutions' (Borzaga, Depedri, \& Tortia, 2009). Within the tourism context, the worker cooperative of the Hotel Bauen in Argentina provides a possible example towards more human-centred development. As expressed by Higgins-Desbiolles (2012:19), '[w]e need to explore alternatives that humanize our economic systems and the Hotel Bauen offers one example in the tourism domain'. In addition, cooperatives can be linked to specific cultural contexts such as van der Walt (2008) who links the African concept of Ubuntu to the collective entrepeneurship approach.

From their Iranian case study, Aref and Gill (2009) suggest that a cooperative can enhance rural tourism development 'through three major capacity levels; community, organizational and individual levels' (see Figure 1). The same authors (Aref \& Gill, 2009:72) conclude that '[t]he main importance approaches which suggested in this study were development of rural cooperatives for rural tourism development. Thus rural cooperatives are a major critical success factor in rural tourism.'

Verma (n.d.) specifically suggests that, '[t]he important role of participatory and community based organisations, like cooperatives, in promoting tourism has yet to be recognised' and the cooperative sector can be a strong protagonist in solving many socio-economic problems and can have an advantage over other types of organisations. The presence of a cooperative system locally controlled can be instrumental in influencing and promoting CBT 


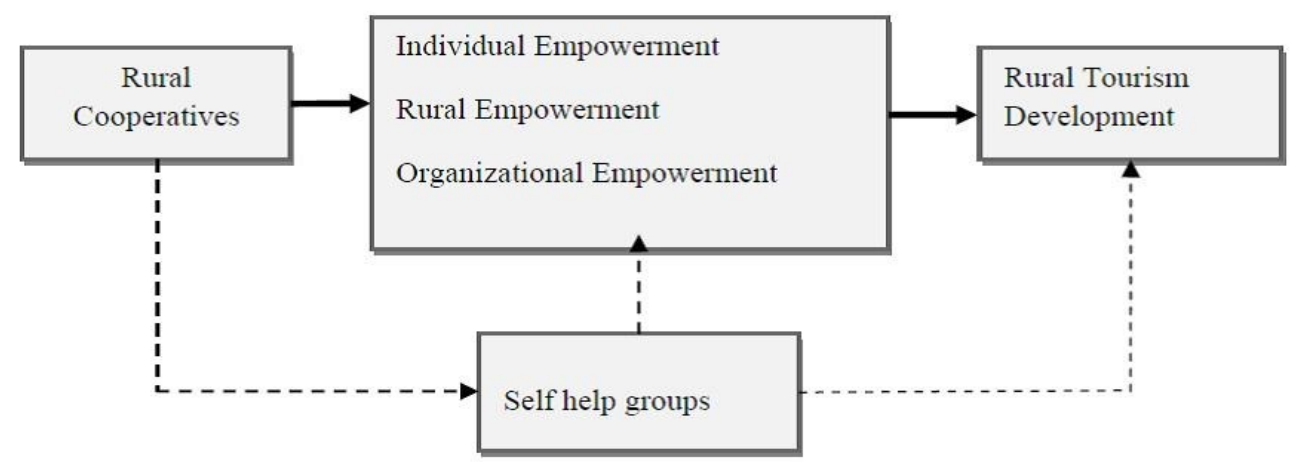

Figure 1. The interactions between rural cooperatives and rural tourism development Source: Adapted from Aref \& Gill (2009:72)

(see Kontogeorgopoulos et al., 2014). The role that cooperatives play in various aspects of CBT has been also recognised, for example, in Romania (lorio \& Corsale, 2014), Malaysia (Mohamad \& Hamzah, 2012), Bali (Byczek, 2011) and Brazil (Mielke, 2012). Again, local tradition and history at community level can form a positive substratum upon which to facilitate CBT development through collective entrepreneurship (Byczek, 2011; Giampiccoli \& Hayward Kalis, 2012a; Kontogeorgopoulos et al., 2014).

Amalgamating the issues of the scale of impact of collective entrepreneurship and democratic features, it is worth quoting what was recently written in a study on Malaysia about the scaling-up of CBT through cooperative business. The study proposes that, despite challenges and pre-requisites, '[c]ommunity cooperative is a business model that has been proven to be instrumental in the growth of community's business ventures. Its bottom-up approach and broad based management thus avoid manipulation by local elites' (Mohamad \& Hamzah, 2012).

This section has reviewed the working of CBT in matters of scale of impact, collective entrepreneurship and the implementation approach using a PPT perspective as a starting point.

\section{Community-based tourism and pro-poor tourism}

The last section addresses the fifth objective, as it proposes a different positioning of this paper by keeping in mind, as a substratum, the various previous sections, and proposes a different positioning of CBT and PPT in relation to community development. The suggestion is that CBT and PPT have a different positing in their role to community development.

The relationship between CBT and PPT in the current neoliberal hegemonic milieu can favour two outcomes (see Figure 2). In the first, CBT is simply interpreted as a PPT strategy, where CBT development is inserted and follows the PPT modus operandi. In this case, CBT has been encapsulated in, and neutralised by, the PPT framework. Within this context, CBT (and its members) remains dependent on the established and mainstream tourism sector. The Pro-Poor Tourism: Annual Register 2006 mentions various CBT research studies and projects in many parts of the world (Pro-poor Tourism Partnership, 2006). One mentioned initiative is the Online Community-based Tourism Directory for Southern Africa supporting the Regional Tourism Organisation for Southern Africa (RETOSA) (Pro-poor Tourism Partnership, 2006). However, Giampiccoli and Mtapuri (2012) propose that this same RETOSA directory interprets CBT in a more flexible manner. They (Giampiccoli \& Mtapuri, 2012:38) offer that, 'different possible levels of community involvement in the CBT ventures are recognized, which also gives ample margin for external actors to interpret (and exploit) the concept of CBT, despite the initial statement stressing that CBT is a contributory component to sustainable development and poverty alleviation.' 
The second possible outcome concerning PPT and CBT implies their divergence. Here, CBT and PPT are not working together but in isolation towards different goals. That is, PPT essentially maintains and perpetuates the status quo of the way the tourism sector is structured and managed; while CBT, on the other hand, works towards the restructuring of the tourism sector through alternative development strategies that favour a rebalancing of the tourism industry towards more equitable control and benefits of local people. In this case, PPT remains (as it is) within a neoliberal framework (Hall, 2007; Schilcher, 2007), 'dictated by corporate and bureaucratic interests whose focus is garnering political support for tourism as a policy priority' (Chok et al., 2007:160). CBT, on the other hand, searches for alternative strategies towards social justice and equity. In addition, a third solution is the temporary link of CBT with the mainstream tourism sector. In this case, PPT and CBT still remain isolated. Therefore, a 'temporary' but long-term partnership is here seen as an option following specific criteria.

The concept of 'temporary partnership' (in Figure 2), in fields such as marketing/market access, quality control, capacity-building/skills development, as already presented by Mtapuri and Giampiccoli (2013), needs to be considered and explained. That is, the 'temporary' partnership is 'temporary' in the sense that the community should be empowered to become independent and to be able to manage alone all the different operations attached to the CBT venture. Only in this way can CBT remain within its initial conceptual understanding and so facilitate community empowerment, self-reliance and sustainability. This will favour the structural adjustment rebalance of the tourism sector and become a reflection (within its relevance limit) of society as a whole in a more just and equitable society. At the same time, it is important to underline that a partnership of a

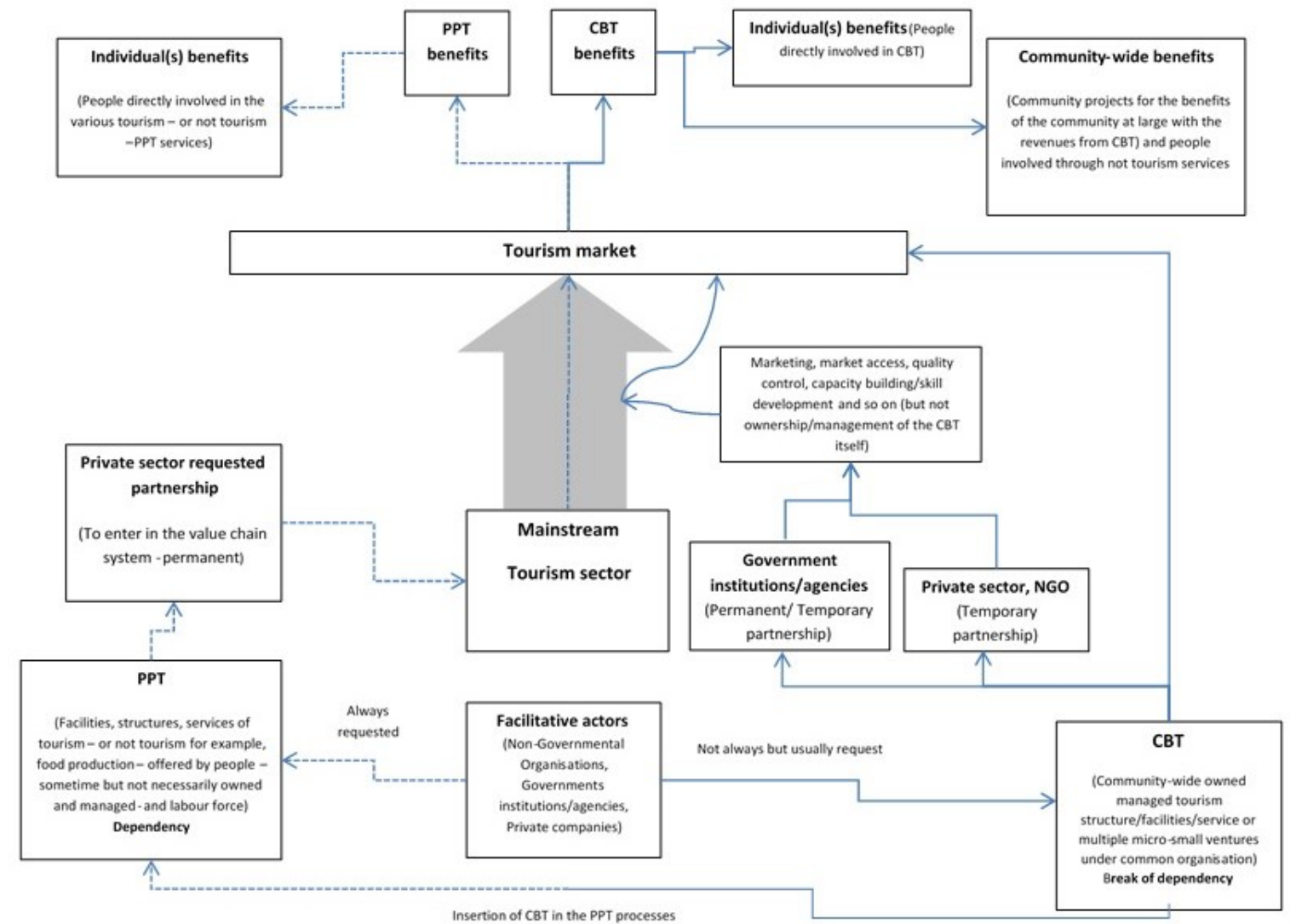

Figure 2. Different path of PPT and CBT towards community benefit

Source: Saayman \& Giampiccoli $(2015: 171)$ 
Table 2. CBT and PPT characteristics

\begin{tabular}{|c|c|}
\hline CBT & PPT \\
\hline Alternative & Neoliberal \\
\hline $\begin{array}{l}\text { Community ownership and management (control) of tourism } \\
\text { structure/facilities }\end{array}$ & $\begin{array}{l}\text { Community ownership and management (control) } \\
\text { not required. Usually externally owned }\end{array}$ \\
\hline $\begin{array}{l}\text { Indigenous outcome (with possible 'temporary' external } \\
\text { support/facilitation/partnership). }\end{array}$ & Externally introduced. \\
\hline Management style based on local culture & Based on Western-based management \\
\hline Holistic approach & More related to economic matters \\
\hline Self-reliance & Dependency \\
\hline Empowerment & Paternalistic \\
\hline Long-term & Short-term \\
\hline Redistributive & Not redistributive \\
\hline Small and large scale & Preferentially large scale \\
\hline Facilitation & Participation \\
\hline $\begin{array}{l}\text { Collective entrepreneurship (or individual enterprises under } \\
\text { umbrella collective organisation) }\end{array}$ & Conventional private companies \\
\hline $\begin{array}{l}\text { Individual and collective benefits and empowerment (direct and } \\
\text { indirect benefit) }\end{array}$ & Individual benefit and empowerment \\
\hline Informal and formal & Formal \\
\hline Bottom-up & Top-down \\
\hline
\end{tabular}

Source: Saayman \& Giampiccoli (2015:172)

CBT venture can be prolonged beyond impermanence. The key and fundamental difference is that the decision by the community to extend the possible partnership has to be seen as a voluntary option - a choice - and not as a required need to sustain the CBT venture. This difference is fundamental because, once the partnership is optional; the community relies on its decision and on its own independence to run the CBT venture, rather than on the external partner. In this sense, the partnership moves toward a rebalanced power relation as the community is not with closed options (that is, forced) to establish the partnership, but has a choice to move (to an always greater degree) to increase its power structure against the external operator. With a rebalanced power position, better conditions in the contract agreement and more balanced benefits are likely to occur. The issues are that during the partnership/facilitation process, the community should be properly facilitated in all aspects related to ownership and management of the CBT ventures and, in another sense, control of the local tourism sector and community development matters (see concept of 'training ground' in Hamzah \& Khalifah, 2009:59; on similar matters see also Hainsworth, 2009:113; Moscardo, 2008:174; Twining-Ward, 2007:14). Ideally, it should be the government that offers proper capacitybuilding and skills development facilitation, with NGOs and the private sector taking part as complimentary actors (Mtapuri \& Giampiccoli, 2013). On the other hand, the private operators are better placed as temporary partners in such specific issues as quality management and marketing/market access, after which the partnership should become, as explained above, a choice instead of a 'forced' need for the community. In particular, the private sector 'can be particularly helpful during the early phases of a CBT initiative' (Asker et al., 2010:82). Therefore, the partnership should be seen simultaneously as being both 'temporary' and long term.

A summarising table (Table 2) of the different characteristics of CBT and PPT can be proposed from the present paper. Table 2 should not be considered rigidly, but rather as a directional trend concerning where CBT and PPT differ and on what they are based.

This final section proposes the difference between CBT and PPT in relation to community development, arguing that while CBT is directed toward a type of tourism development that promotes community development, PPT is not. As such, tourism development within a CBT approach remains outside (if not for the possible temporary/long term partnership) the mainstream tourism structure and development approach, while PPT is firmly anchored within this last framework. 


\section{Between CBT and PPT}

This section, with some possible conceptual repetition from previous sections, illustrates a case study based on literature that considers both CBT and PPT angles. An example from Peru seems to indicate how mainstream external controlled tourism seems to militate against the originally locally developed and controlled CBT forms. Mitchell and Muckosy (2008:2) suggest that 'Previous experiments with collective management structures were abandoned as they undermined incentives to work. A review of the CBT project on Taquile Island in Lake Titicaca, Peru, reveals that only four of the 19 tourist boats are still considered cooperatives and only one of the 10 restaurants is community-owned.' The same authors Mitchell and Muckosy (2008) argue that in general in PPT greater involvement of mainstream tourism is, instead, necessary. Mitchell and Muckosy (2008:2) writing on a critic to CBT they think that:

development practitioners who focus on a critique of mainstream tourism may be doing local communities a disservice. Many community-based tourist initiatives are ineffective at reducing poverty at scale, and recent research suggests sizeable and sustainable transfers of benefits from affluent tourists to poor communities are possible - but only if practitioners recognise that it is linkages with, and not protection from, the mainstream industry that benefit poor communities.

From a PPT angle, Mitchell and Muckosy (2008:2) suggest that '[t]he Taquile Island community on Lake Titicaca, for example, has achieved this [link to mainstream tourism] by connecting local communities to a major tourism route.' Despite Mitchell and Muckosy (2008:2) suggestions it has been also noted (see Mitchell \& Reid, 2001:136) time ago that

Historically, the strong interaction between community solidarity and communal action allowed various catalysts to help turn tourism awareness into product at a community-wide level. Traditional power structures and processes on the island are largely responsible for transparent and consensual decision-making. Taquile has directed its own tourism planning and development through self-awareness and self-reliance, and a relatively fair and balanced power structure has facilitated a community-based tourism product. Admittedly, local control in decision-making in Taquile has diminished as Puno travel agencies are increasingly obtaining a large market share. Still, the community is relatively self-reliant with little outside interference in local politics and decisionmaking. Collective management of local services is also high, especially for handicrafts, accommodation, and entrance fee collection (Mitchell \& Reid, 2001:136).

This last quote also show, as previously already proposed, specific cultural context can favour collective management, community-wide benefit and indigenous power structures can work in a 'transparent and consensual decision-making' way. The study concludes by suggesting that: 'In spite of the generally positive assertions about tourism integration in the community of Taquile, there are some darker clouds on the horizon that could dismantle this healthy balance. Change is taking place here as elsewhere in the world. The forces of globalization and the move to freer markets are being felt everywhere, even in previously isolated Andean communities [and] that integration of tourism into the socioeconomic life of the community has relied on the tender balance between liberal market forces and collective participation, control, and benefit' (Mitchell \& Reid, 2001:136-137). More recently similar conclusion has been reached indicating: '[f]irstly, Taquileans initiated development tourism on their island themselves, and, secondly, just participating in tourism is not sufficient for them - they strive for control' (Ypeij \& Zorn, 2007:119). That is the local community started the tourism development process and benefits from it, '[t]ourism to Taquile started in 1976 [...] in those early days especially, Taquileans managed to control the tourist trade, and they have reaped its economic and social benefits' (Ypeij \& Zorn, 2007:119). However, Ypeij \& Zorn, (2007) explain how the neoliberal framework was able to decrease the local community control over tourism. They states: 'In the last decade, they have been losing this 
control because of the liberalization of markets, the booming character of tourism growth and the new actors who have appeared on the scene and who are willing to struggle with the Taquileans over tourism's benefits' (Ypeij \& Zorn, 2007:119). Nevertheless, as a proof of Williams suggestion that, "hegemony is not singular; indeed that its own internal structures are highly complex, and have continually to be renewed, recreated and defended; and by the same token, that they can be continually challenged and in certain respects modified" (Williams, 1976:205) '[t]he islanders are currently engaged in a serious struggle to regain and maintain their control of tourism to their island community' (Ypeij \& Zorn, 2007:119).

It is the level and type of inclusion can give advantage to neoliberal forces that are more skilled and prepared in managing tourism at the global scale. Globally however the reality is unfavourable to local community, 'the reality is that in many countries, control often remains vested in the hands of outsiders, such that local communities are often only incorporated at a subservient level' (Binns \& Nel, 2002:238). The PPT perspective works within a neoliberal framework that does not change the structure of power as instead aimed by CBT. Asker et al. (2010:129) also comments that Taquile

In the early days the Taquileans were able to control the tourist industry and develop a community-based model that followed their traditional participative model of governance [...]. However since the 1980s the Taquileans have faced increasing pressure from mass tourism and neo-liberal policies that have threatened their ability to control and benefit from the tourism on their island. The neo-liberal Fujimori led Peruvian government abolished the boat monopoly and stopped the Taquileans from charging an entrance fee to their island. Increasingly tourists are not staying overnight but simply visiting for a day as part of a two-day tour on the Titicacan islands. In 2005 just $5 \%$ of tourists stayed in Tacquile overnight. The Taquileans have attempted to resist this trend by promoting community based cultural tours of the island [...] This transition from a culturally based CBT model of tourism to mass day tourism has placed the
Taquileans in an increasingly passive role as 'objects of the tourist gaze'.

The same authors (Asker et al. (2010:129) give some lesson learned by suggesting:

Unlike many neighbouring islands the Taquilean community decided not to sell any of their land to outsiders, this has allowed them to keep a much higher level of control over the tourist infrastructure and industry than their neighbours. The community based model using rotating governance positions, ad hoc committees and cooperative enterprises allowed all Taquileans to have an input into the development of tourism on their island and to share in the benefits it provided. This model derived the Maximum benefit to the local population whilst also providing an engaging and fulfilling service for the tourists. The goal of the community was not only the participation in the tourist industry, but rather control of it and the ability to shape their own economic future. The arrival of uncontrolled mass tourism, where outsiders largely garner the benefits, has had a disruptive effect on the social organisation and indigenous culture of the island. The national governments' market based policies and lack of support for local management of the industry have enabled the situation to occur. Support from international NGOs for the Taquileans to develop the technical skills needed to promote their CBT model on the Internet is helping them to begin to reassert control over the industry.

Raffo and Wust (n.d., 23; see also Bardales Vassi, 2004) show the sequence of events and the wish of the community to go back the original system of tourism development.

Since the beginning of the community-based tourism venture in Taquile, up until the mid$80 \mathrm{~s}$, tourism was controlled by the islanders. The boats belonged to the members of the community, and lodging and meals were offered in each home but were managed collectively. Under this same communitarian principle the handicrafts store, which is still open, was established. The community managed all the activities within a frame of 
general wellbeing, and this contributed to maintain a series of traditions in a homogenous manner, particularly-regarding the conservation of the old town of stone houses. By the end of the 1980 decade, an intensive tourism was unleashed which made the town grow, and promoted changes in management, which acquired a more individual character. The lodging houses were singled out and there was a proliferation of small restaurants and handicraft stores. There were many changes in Taquile, yet the process was not free from conflicts; however, at present, people from the island are rescuing the roots of the original project.

Associated with the fact that, as previously maintained, CBT can grow it is important to notice that the tourism in Taquile is growing and, as much as difficulties arise (as will happen in any circumstance and any type of organisation when fast grow happen), the community is striving to maintain its independence and control, although uncertainty is present. This fact can be seen as written in Raffo and Wust (n.d.:25; originally in Bardales Vassi, 2004:4):

The community, which reaches the two thousand inhabitants, now receives about 50 thousand tourists per year, 25 times its population. A situation of such breadth presents great challenges for the organizational capacities of any tourist centre, and particularly in the case of Taquile, which lacks the business character needed for these sorts of activities and that barely counts with $12 \mathrm{~km}^{2}$, most of which are rocky slopes. At present, Taquile is resistant to the influence of foreign cultures, and the main preoccupation of the islander is the proper management of this activity that has become their main source of income. Between the years 1991 and 1992, 87\% of visitors were foreigners. This same influx could signify the progressive loss of their culture, which is their main social capital.

In Taquile the communitarian values to control and manage the tourism sector together as a community, risk to be jeopardised by mainstream tourism. Therefore, the community tries to resist and reinsert in their life the original communitarian approach. It could be that the lesson to be learnt is to allow different community to choose, and be facilitate to ameliorate depending on, their needs and desires instead of preconception externally structured opinions and strategies. In Taquile for example it seems that although not perfect and with difficulties the collective management approach is preferred by the local community, it can work and, possibly, if properly supported can increase always more the value of tourism and the benefits to local people.

\section{Conclusion}

The objectives of the paper have been to contextualise the relationship between tourism and development within the neoliberal milieu, to review issues related to CBT and successively to PPT, to investigate specific matters of the scale of impact, implementation approach, collective entrepreneurship and governments' role in CBT and PPT, and finally, to propose a different positioning of CBT and PPT in relation to community development.

The result of the first objective shows that tourism is currently driven by and managed within the current neoliberal milieu tourism serve the aim of the capital and did not promote wide poverty alleviation and redistribution of wealth and resources. There is a need to understand the specific role of tourism in the global neoliberal framework and how this facilitates (or not) poverty reduction and community development. This objective also shows that community development must be understood in its holistic sense and not only associated with numerical economic interpretations. External actors can positively or negatively influence CBT development.

Objective two shows that CBT has various characteristics and interpretations and it is often manipulated and managed from a neoliberal perspective that does not represent CBT's original and proper aim, which is to work towards social justice and a holistic redistribution of wealth and resources. The third objective proposes that the origin and strategies of PPT do not counteract neoliberal forces but, instead, it is associated with them. As such PPT does not work towards 
restructuring the tourism industry itself (as CBT does), but it follows the neoliberal approach of development making the pro-poor as a voluntary action. PPT forces tend to insert the CBT approach within their parameter of action.

Objective fourth results propose that while CBT is usually interpreted as a small scale development it should be, instead, also proposed in, and directed to, large scale of development. PPT tends to be more associated with large-scale development. In addition, the implementation approach to CBT is fundamental to determine a positive or negative result in CBT development. However, often there is no proper implementation of CBT projects and therefore projects fail. Finally, the fourth objective shows that, contrary to what is suggested from a PPT perspective, collective entrepreneurship is, indeed, a very valid option in CBT development as well as for socioeconomic development in general.

The final objective was the concluding objective of this review and it suggests that CBT and PPT have been found to be different, mostly fundamentally divergent, in their position towards holistic community development. While PPT remains within the neoliberal framework, CBT entails its restructuring. In addition, PPT seems to try to absorb, co-opt and reshape CBT towards parameters more aligned with neoliberalism and PPT itself. Therefore, a better understanding of specific terminologies and their actual role need to be advanced to propose how specific discourse, such as PPT discourse, aims to associate alternative development with a camouflage of 'alternative terminology'. This paper is relevant because there is a need to examine and dismantle the hegemonic discourse of neoliberal globalisation in tourism as proposed by PPT, because tourism is seen as a principal tool in growth and development within many disadvantaged contexts. Within this context, the role of tourism in community development, as a main economic global sector, cannot be underestimated. The contribution of the paper pertains to a greater understanding of the correlation between tourism, development theories and community development.
This research argues that PPT is a strategy of tourism development for poor communities' development that, in practical terms, is skewed and partial as it remains within, is supported by, and is supportive of, the contemporary hegemonic system that favours the neoliberal private capital (especially large companies) expansion of their market share and control of the tourism sector (and associated use of the sector attraction resources both natural and cultural) in always greater geographical spaces. Within this context, PPT serves to maintain the status quo and to reinforce the present tourism sector's structure that preserves an unbalanced and skewed distribution of control, resources, capacities and benefits in favour of specific actors and entities that rely on, are supportive of, and supported by (that is, they represent and validate) the present hegemonic system. Specific strategies and policies are seen as rational as 'the only way possible' and as similar to the 'TINA' approach within the contemporary context.

Firstly, PPT has been elaborated upon and developed within the hegemonic neoliberal framework; secondly, PPT as practiced today tends not to be flexible enough to appreciate and insert local realities that differ from the mainstream development hegemonic paradigm; and thirdly, PPT is based on a voluntary willingness by the tourism industry to support PPT instead of being legally obligated to do so. Finally, as a consequence of the previous matters, PPT does not intend to be redistributive (Chok et al, 2007), does not serve to change the status quo of the tourism sector, but on the contrary, rather works for the reinforcement of it with the continuing unbalanced distribution of control, capacities, resources and benefits, incorporating the poor only within the limit that maintains them in a dependency framework on external private capital and 'expertise'.

CBT, on the other hand, and in relation to the same matters, works within the local cultural context (CBT sees the cultural context as fundamental). It works outside (or parallel) to the hegemonic framer by striving towards the facilitation of alternative paths of development that fit the local context and are flexible, while it 
works towards the legalisation of specific rights of ownership and control of the tourism sector at community level. Finally, it works to break the dependency framework within which the poor are, and to emancipate by means of the redistributive measures of control, resources, capacities and benefits of the tourism sector. Nevertheless, this analysis does not mean to suggest that CBT development is without problems and difficulties and, depending upon each case, possible limitations. It rather intends to argue the fundamental difference between CBT and PPT in relation to community development intended as an empowerment, emancipatory and holistic understanding tool.

CBT works towards the shift of control, ownership and management within the tourism sector in favour of the excluded, marginalised and poor (who, many times, are those who live in places rich in tourism attraction resources and/or represent the attraction themselves). On the contrary, PPT is not seen as pushing for these redistributive strategies, but instead proposes the 'insertion' (on unspecified terms and conditions) of the poor in mainstream tourism, leaving unaltered the fundamental and unequal distribution of power and control of the industry.

PPT is considered as the final thought as a tourism development strategy directed towards poverty alleviation (see above Mitchell, 2010:6). However, one should be reminded of Peet's (2003:16-17) words: 'Economic policy does not come from science's ability to mirror the exact structure of social reality in the structure of truthful statements called exact theories. Instead, policy is socially produced by a community of experts who agree, more by convention or political persuasion than factual backing, to call a certain type of thinking and speaking 'rational' [...] depth of a hegemony resides in the ability of a discursive formation to specify the parameters of the practical, the realistic and the sensible among a group of theoreticians, political practitioners and policy makers [and] where critical discussion is limited to variants of a given discourse.'

Critical perspectives on CBT should be welcomed and encouraged, as it is criticism that grows a discipline. However, the specific procedure of intervention and influence on CBT projects should be seen as a key determinant to verify the proper advancement of CBT development. It is not appropriate to judge the failure of CBT as a concept or practical intervention when in most (that is, almost all) cases, its own development has been incorrectly facilitated and managed. CBT should not be seen and facilitated/implemented in a neoliberal framework of judgments and practices, but coherently in alternative development strategies (as it is one of them) that break the dependency framework based on neoliberal structures of power. This implies that it should be read within alternative development approaches that remain outside the 'TINA' agenda.

On the other hand, and despite the challenges and difficulties, the need is to work towards endogenous development (with which CBT is associated) that favours human needs and capacities instead of the needs of the capital, thereby promoting 'real endogenous development means making real the preferential option for the poor' (Lebowitz, 2004:22). A break from capital-oriented policies (and not to see them as the only way possible) and to seek alternative development approaches are needed (Lebowitz, 2004).

Nevertheless, PPT remains within the neoliberal discourse (it supports and is supported by it) that continues to perpetuate unequal distributive patterns of resources, benefits and power as, 'on a global scale, PPT advocates must be explicit about the fact that stakeholders include winners and losers working on a vastly uneven playing field' (Chok, et al., 2007:159). Instead, community-based development, and CBT within it, works towards social justice, equity, empowerment, sustainability and the self-reliance ${ }^{4}$ of disadvantaged community members. Within this context, 'to be really affective, PPT must be integrated in a broad community-based development strategy' (Karim, Mohammad \& Serafino, 2012) and not vice versa. Overall, CBEs emerge as the result of the desire of communities to gain or regain control of their own local development. (Peredo \& Chrisman, 2006). 


\section{Endnotes:}

${ }^{1}$ The pro-poor tourism network was formed by the SNV (Wehkamp, 2007, p. 6).

${ }^{2}$ In South Africa, it has been reported that while '[t]ourism's contribution to the economy increased by an estimated $2.7 \%$ from R184,4 billion in 2008 to R189,4 billion in 2009, resulting in an overall contribution of $7.9 \%$ to the GDP. However, the number of tourism jobs (direct and indirect) decreased by $-7.4 \%$ from 993,400 in 2008 to 919,800 in 2009' (SATOUR, 2010:5). Therefore, more insight analysis on tourism development that goes beyind mere numerical growth, but includes the tourism sector structure should be at the forefront if tourism is to serve as a mechanism for wider community development.

3 'Passive' participation is described (based on Pretty, 1995, p. 4-5) 'as participation where people participate by being told what has already been decided or happened. It involves unilateral announcements by administrators or programme management without listening to people's responses, and control of the information flow by the same agents' (Wright, 2005 , p. 107). For a more comprehensive analysis of the EU-supported Wild Coast project see: ECODES (2003), Giampiccoli (2010), Wright (2005), Ntshona \& Lahiff (2003), and Kepe et al., (2001), Russell \& Kuiper (2003); Giampiccoli \& Hyward Kalis (2012).

Where self-reliance 'does not imply isolationism, either politically or economically. It means that we shall depend on ourselves, not on others. But this is not the same thing as saying we shall not trade with other people or co-operate with them when it is to mutual benefit' (Nyerere, 1974:99).

\section{References}

Acheampong, K. O. (2010) Political ideologies and their impacts on space economies: $A$ study in the spatial manifestation of tourism activities in the Eastern Cape Province of South Africa. Paper presented at the International Conference on Applied Business Research, 29 November - 3 December 2010, Ras Al Khaimah, United Arab Emirates.

Adams, W. M. (2001) Green Development: Environment and sustainability in the Third World. London: Routledge.
Akunaay, M., Nelson, F., \& Singleton, E. (2003) Community Based Tourism in Tanzania: Potential and Perils in Practice. Paper presented at the $2^{\text {nd }}$ Peace through Tourism Conference $7-12^{\text {th }}$ December 2003, Dar Es Salaam, Tanzania.

Amat Ramsa, Y., \& A. Mohd. (2004) Community-based Ecotourism: A New proposition for Sustainable Development and Environmental Conservation in Malaysia. Journal of Applied Science, 4 (4), 583-589

Aref, F., Gill, S.S., \& Aref, F. (2010) Tourism Development in Local Communities: As a Community Development Approach. Journal of American Science, 6 (2), 155-160

Aref, F., \& Redzuan, M. (2009) Community Leaders' Perceptions toward Tourism Impacts and Level of Community Capacity Building in Tourism Development. Journal of Sustainable Development, 2(3), 208-213

Aref, F. (2011) Barriers to community capacity building for tourism development in communities in Shiraz, Iran. Journal of Sustainable Tourism, 19(3), 347-359

Asker, S., Boronyak, L., Carrard, N., \& Paddon M. (2010) Effective community based tourism: a best practice manual. APEC Tourism Working Group. Griffith University: Sustainable Tourism Cooperative Research Centre.

Baktygulov, S., \& Raeva, R. (2010) Creating Value for All: Community-Based Tourism. New York: United Nations Development Programme.

Baran, P. (1962) The political Economy of Growth. New York: Monthly Review Press.

Bardales Vassi, R. (2004). Desarrollo turístico e identidad cultural. La Experiencia de la Comunidad de Taquile, en Puno. Programa de las Naciones Unidas para el Desarrollo PNUD. URL : http://www.centrodesarrollo humano.org/pmb/opac_css/doc_num.php?e xplnum_id=749 (Accessed 14.08.2015).

Barratt Brown, M. (1995) Models in political economy. London: Penguin Books Ltd.

Beeton, S. (2006) Community Development through Tourism. Collingwood: Landlinks Press.

Bellamy Foster J., McChesney, R.W., \& Jamil, J.R. (2011) The Internationalization of Monopoly Capital. Monthly Review, (63), 2 
Bianchi, R.V. (2002) Toward a New Political Economy of Global Tourism. In Sharpley, R., D.J. Telfer, (ed.)(2002), Tourism and Development Concepts and Issues. Clevedon: Channel View Publications, 265299

Bianchi, R.V. (2009) The 'Critical Turn' in Tourism Studies: A Radical Critique. Tourism Geographies, 11(4), 484-504

Bianchi, R.V. (2010) Tourism, capitalism and Marxist political economy. In Mosedale, J. (ed.) (2010) Political economy of tourism. A critical perspective. London: Routledge, 1737

Bianchi, R.V. (2011) A Radical departure. A critique of the critical turn in tourism studies. In Wilson, J. (ed.) (2011) Routledge Handbook of Tourism Geographies. London: Routledge, 46-54

Bieler A., \& Morton, D. (2004) A Critical Theory Route to Hegemony, World Order and Historical Change: Neo-Gramscian Perspectives in International Relations. Capital and Class, 82(1), 85-113

Binns, T. (2002) Dualistic and unilinear concepts of development. In Desai, V. \& R.B. Potter (ed.) (2002) The Companion to Development Studies. London: Arnold, 7579.

Binns, T. \& Nel, E. (2002). Tourism as a local development strategy in South Africa. The Geographical Journal, 168(3), 235-247.

Binswanger, H. P. \& Aiyar, S.A. (2003) Scaling up community-driven development theoretical underpinnings and program design implications. World Bank Policy Research Working Paper 3039.

Blackstock, K. (2005) A critical look at community based tourism. Community Development Journal, 40(1), 39-49

Boggs, L. (2004) Community-based natural resource management in the Okavango Delta. In Fabricius, C. (Ed.) (2004) Rights, resources and rural development. Community-based natural resource management in Southern Africa. London: Earthscan, 147-159

Borzaga, C., Depedri, S., \& Tortia, E. (2009) The role of cooperative and social enterprises: a multifaceted approach for an economic pluralism. Euricse Working Papers, N. 000 | 09.
Bramwell, B. \& Lane, B. (2010) Sustainable tourism and the evolving roles of government planning. Journal of Sustainable Tourism, 18(1), 1-5

Britton, S.G. (1981) Tourism, Dependency and Development: a mode of analysis. Canberra: Australian National University Press.

Britton, S.G. (1991) Tourism capital and place: towards a critical geography of tourism. Environmental and Planning, 9(1), 451-478

Butler, G. (2005) Sustainable communities: the important role of local government in building social capital. $2^{\text {nd }}$ Future of Australia's Country Towns Conference, Bendigo, $11^{\text {th }}-13^{\text {th }}$ July, 2005, Bendigo

Byczek, C. (2011) Blessings for All? Community-Based Ecotourism in Bali between Global, National, and Local Interests - A Case Study. Austrian Journal of South-East Asian Studies, 4(1), 81-106

Calanog, L.A., Reyes, D.P.T., \& Eugenio, V.F. (2012) Making Ecotourism Work. A Manual on Establishing Community-based Ecotourism Enterprise (CBEE) in the Philippines. Philippines office: Japan International Cooperation Agency.

Cattarinich, X. (2001) Pro-poor tourism initiatives in developing countries: Analysis of secondary case studies. PPT Working Paper No. 8. Overseas Development Institute (ODI), the International Institute for Environment and Development (IIED), the Centre for Responsible Tourism at the University of Greenwich (CRT). URL: http://www.dfid.gov.uk/r4d/PDF/Outputs/Mis SPC/R7557-PPT8.pdf (Accessed on 30.08.2011)

CBI. (2011) Trends and segments for CBT. Ministry of Foreign Affairs of the Netherlands CBI - Centre for the Promotion of Imports from developing countries.

Chambers, R. (1983) Rural Development: Putting the Last First. Harlow: Longman.

Chok, S., Macbeth, J., \& Warren, C. (2007) Tourism as a Tool for Poverty Alleviation: A Critical Analysis of 'Pro-Poor Tourism' and Implications for Sustainability. Current Issues in Tourism, 10(2/3), 144-165

Cole, S., \& Morgan, N. (2010) Introduction: tourism and inequality. In Cole, S. \& N. Morgan (ed.) (2010) Tourism and inequality. 
Problems and prospects Wallingford: CABI, xv-xxiii

Coop, (2012a) International Year of Cooperatives by the United Nations. United Nations International Year of Co-operatives. URL: http://2012.coop/ (Accessed on 12.06.2012)

Coop, (2012b) Co-operative facts and figures. United Nations International Year of Cooperatives. URL: http://2012.coop/en/ica/ co-operative-facts-figures (Accessed on 12.06.2012)

Cornelissen, S. (2005) The Global Tourism System: Governance, Development and Lessons from South Africa. Aldershot: Ashgate.

Cox, R.W. (1996a) Social forces, states and world orders: beyond international relation theory. In Cox, R.W. \& T.J. Sinclair (ed.) (1996) Approach to World Order. Cambridge: Cambridge University Press, 85-123

Cox, R.W. (1996b) Gramsci, hegemony and international relations: an essay in method. In Cox, R.W. \& T.J. Sinclair (ed.) (1996) Approach to World Order. Cambridge: Cambridge University Press, 124-143

De Beer, F. \& Marais, M. (2005) Rural communities, the natural environment and development: some challenges, some successes. Community Development Journal, 40(1), 50-61

De Kadt, E. (1979) Social planning for tourism in the developing countries. Annals of Tourism Research, 6(1), 36-48

De Martino, G. (2003) Free trade or social tariffs? In Michie, J. (ed.) (2003) The handbook of globalization. Cheltenham, Northampton: Edward Elgar Publishing, 402-412

Denman, R. (2001) Guidelines for communitybased ecotourism development. Gland: WWF International.

Dixey, L. (2005) Inventory and Analysis of Community Based Tourism in Zambia. Prepared for: Production, Finance and Technology (PROFIT). URL:http://www.aec .msu.edu/fs2/zambia/resources/PROFIT\%2 0Community\%20Tourism\%20Survey\%20\%20Final\%20CBT\%20Report.pdf (Accessed 25.05.2012)

Dichter, G. \& Dall'Ara, G. (n.d.) Albergo diffuso developing tourism through innovation and tradition. IDEASS - Innovation by Development and South-South Cooperation. URL: http://www.ideassonline.org/public/ pdf/br_47_01.pdf (Accessed 14.03.2015)

Drumm, A. (1998) New approaches to community-based ecotourism management. In Lindberg, K., M. Epler Wood, \& D. Engeldrum (ed.) (1998) Ecotourism: a Guide for Planners and Managers. Volume 2. North Bennington: The Ecotourism Society, 197-213

Duffy, R. (2014). Interactive elephants: Nature, tourism and neoliberalism. Annals of Tourism Research, 44, 88-101.

ECODES, Consortium. (2003) The Republic of South Africa. Support to the Wild Coast Spatial Development Initiative Pilot Programme Mid-Term Review: European Commission.

Escobar, A. (1995) Encountering Development: The making and unmaking of the Third World. Princeton: Princeton University Press.

Faulkenberry, L.V., Coggeshall, J.M., Backman, K., \& Backman, S. (2000) A Culture of Servitude: The Impact of Tourism and Development on South Carolina's Coast. Human Organization, 59(1), 86-95

Fennell, D.A. (2006) Tourism ethics. Clevedon: Channel View Publication.

Fernandes, C. (2011) The role of local networking in facilitating community tourism development. Paper presented at the International Conference on Tourism and Management Studies, Algarve.

Fields Z. (2011) Efficiency and Equity. The Empresas Recuperadas of Argentina. Latin American Perspectives, 163(35-6), 83-92

Fonchingong C.C., \& Fonjong L.N. (2003) The concept of self-reliance in community development initiatives in the Cameroon grassfields. Nordic Journal of African Studies, 12(2), 196-219.

Forstner, K. (2004) Community Ventures and Access to Markets: The Role of Intermediaries in Marketing Rural Tourism Products. Development Policy Review, 22(5), 497-514

Foucault, M. (1972) The archaeology of knowledge. New York: Arper and Row.

France, L. (1997) The Earthscan Reader in Sustainable Tourism. London: Earthscan Publ. Ltd. 
Frank, A.G. (1966) The Development of Underdevelopment. Monthly Review, 18(4), 17-31

Frank, A.G. (1969) Capitalism and underdevelopment in Latin America. Historical studies of Chile and Brazil. New York: Monthly Press Review.

Frank, A.G. (1988) The Development of Underdevelopment. In Wilber, C.K. (ed.) (1988) The Political Economy of development and Underdevelopment New York: Random House Business Division, 109-119

Gartner, C., \& Cukier, J. (2012) Is tourism employment a sufficient mechanism for poverty reduction? A case study from Nkhata Bay, Malawi. Current Issues in Tourism, 15(6), 545-562.

Gascón, J. 2013. The limitations of communitybased tourism as an instrument of development cooperation: the value of the Social Vocation of the Territory concept. Journal of Sustainable Tourism, 21:5, 716731.

Giampiccoli, A., \& Hayward Kalis J. (2012a) Community-based tourism and local culture: the case of the amaMpondo. Pasos. Revista de Tourism y patrimonio Cultural, 10(1), 173-188

Giampiccoli, A., \& Hayward Kalis, J. (2012b) Tourism and food: a possible linkage of community-based tourism, local foods and community development. A Mpondoland case study. Journal of Culture and Agriculture. Culture, Agriculture, Food and Environment, 34(2), 101-123.

Giampiccoli, A., \& Mtapuri, O. (2012) Community-Based Tourism: An Exploration of the Concept(s) from a Political Perspective. Tourism Review International, 16(1), 29-43

Giampiccoli, A. (2007) Hegemony, Globalization and Tourism Policies in Developing Countries. In Burns, P.M. \& M. Novelli (ed.) (2007) Tourism and politics. Global framework and local realities. Oxford: Pergamon, 175-191

Giampiccoli, A., \& Nauright, J. (2010) Problems and Prospects for Community-based Tourism in the New South Africa: The 2010 FIFA World Cup and Beyond. African Historical Review, 42 (1), 42-62
Gillespie, S. (2004) Scaling up communitydriven development: A synthesis of experience. FCND Discussion Paper No. 181. Washington: International Food Policy Research Institute.

Goodwin, H. (2006). Community-based tourism: failing to deliver? URL: http://www.eldis.org/id21ext/insights62art6.h tml (Accessed 14.08.2015).

Goodwin, H. \& Santilli, R. (2009). Communitybased tourism: a success? International Centre for Responsible Tourism. ICRT Occasional Paper No. 11. URL: http://www.haroldgoodwin.info/uploads/cbta successpubpdf.pdf (Accessed 14.08.2015).

Goodwin, H., Spenceley, A., \& Maynard B. (no date) Development of Responsible Tourism Guidelines for South Africa. NRI Report No: 2692. Project Code: V0149. Rural Livelihoods and the Tourism Industry. URL:http://anna.spenceley.co.uk/files/Respo nsibleTourismGuidelinesGoodwinSpenceley Maynard.pdf (Accessed 10.06.2011)

Gosovic, B. (2000) Global intellectual hegemony and the international development agenda. International Social Science Journal, 52(166), 447-456

Goulet, D. (1971) The cruel choice: a new concept in the theory of development. Center for the Study of Development and Social Change. New York: Atheneum.

Graham, J.D. (1976) Julius Nyerere: A Contemporary Philosopher-Statesman, Africa Today, 23(4), 67-73

López-Guzmán, T., Sánchez-Cañizares, S., \& Pavón V. (2011) Community-based tourism in developing countries: a case study. Tourismos: an International Multidisciplinary Journal of Tourism, 6(1), 69-84

Hainsworth, D. (2009) Community Tourism and Broad-based Local Development: The Case of Doi Village, Thua Then province, Vietnam. In Jigang, B.A.O. (ed.) (2009) Tourism and community development. Asian Practices. World Tourism Organization:Madrid, 121-134

Hall, M.C. (1998) Tourism and Politics Policy, Power and Place. Chichester: John Wiley and Sons.

Hall, M.C. (2007) Editorial. Pro-poor tourism: do 'tourism exchange benefit primary the countries of the south'? In Hall, M. (ed.) (2007) Pro-poor tourism: who benefits? 
Perspective on tourism and poverty reduction Clevedon: Channel View Publications, 1-7

Hamzah, A., \& Khalifah, Z. (2009) Handbook on community based tourism 'How to develop and sustain CBT. Kuala Lumpur: Asia-Pacific Economic Cooperation Secretariat.

Harris, R.W. (2009) Tourism in Bario, Sarawak, Malaysia: A Case Study of Pro-poor Community-based Tourism Integrated into Community Development. Asia Pacific Journal of Tourism Research, 14(2), 125135

Harrison, D. (2008) Pro-poor tourism: a critique. Third World Quarterly, 29(5), 851868

Harrison, D., \& Schipani, S. (2007) Lao tourism and poverty alleviation: community-based tourism and the private sector. In Hall, C.M. (Ed.) (2007) Pro-poor Tourism: Who Benefits? Perspective on Tourism and Poverty Reduction Clevedon: Channel View Publications, 84-120

Harvey, D. (2007) A Brief History of Neoliberalism. Oxford: Oxford University Press.

Häusler, N., \& Strasdas, W. (2003) Training Manual for Community-based Tourism. Zschortau: InWEnt - Capacity Building International.

Hawkins, D.E., \& Mann, S. (2007) The World Bank's role in tourism development. Annals of Tourism Research, 34(2), 348-363

Hayle C. (n.d.). Ensuring Market Realism and Effective Promotion. URL: http://www. mona.uwi.edu/jct/aboutct/products.htm (Accessed on 31.01.2011)

Higgins-Desbiolle, F. (2006). More than an "industry": The forgotten power of tourism as a social force. Tourism Management, 27, 1192-1208.

Higgins-Desbiolles, F. (2012) The hotel Bauen's challenge to Cannibalizing capitalism. Annals of Tourism Research, 39(2), 620-640

Hunter Wade, R. (2004) Is Globalization Reducing Poverty and Inequality? World Development, 32(4), 567-589

Ife, J. (2002) Community Development: Community-based alternative in the age of Globalisation. Sydney: Pearson Education.
ILO - International Labour Organization. (2001) Human resources development, employment and globalization in the hotel, catering and tourism sector. Geneva: International Labour Organization.

loannides, D. (1995) Strengthening the Ties between Tourism and Economic Geography: A Theoretical Agenda. The Professional Geographer, 47(1), 49-60

Iorio, M., \& Corsale, A. (2014) Communitybased tourism and networking: Viscri, Romania. Journal of Sustainable Tourism, 22(2), 234-255

Ivanov, S. \& Webster, C. (2013a). Globalisation as a driver of destination competitiveness. Annals of Tourism Research, 43, 628-633.

Ivanov, S. \& Webster, C. (2013b). Tourism's impact on growth: the role of globalisation. Annals of Tourism Research, 41, 231-236.

Jamieson, W., \& Sunalai, P. (2009). Community-based tourism planning in Klong Khwang, Thailand. In Jigang, B.A.O. (ed.) (2009) Tourism and community development. Asian practices. World Tourism Organization: Madrid, 77-96

Jamieson, W., \& Nadkarni, S. (2009) Editorial: A Reality Check of Tourism's Potential as a Development Tool. Asia Pacific Journal of Tourism Research, 14(2), 111-123

Jänis, J. (2009) Tourism Development Strategies in Namibia: Private and Community Perceptions on the National Policy. In Hottola, P. (ed.) (2009) Tourism Strategies and Local Responses in Southern Africa. Wallingford: CAB International, 1-7

Jealous, V. (1998) CBST: The Philippine perspective, criteria \& goal for each NGO/PO/Community. In Urquico, C.T. (ed.) (1998) Community based Sustainable Tourism. A handbook. Quezon City: Accessing Support Service and Entrepreneurial Technology, 8-12

Johnson, P. A. (2010) Realizing Rural Community Based Tourism Development: Prospects for Social-Economy Enterprises. Journal of Rural and Community Development, 5(1/2), 150-162

Kalb, D. (2005) From flows to violence. Politics and knowledge in the debates on globalization and empire. Anthropological Theory, 5(2), 176-204 
Karim, R., Mohammad, F., \& Serafino, L. (2012) Integrating pro-poor tourism activities in a community-based idea of development: the case of the district of Hunza-Neger, Pakistan. Paper presented at the International Colloquium on Tourism and Leisure (ICTL). $9^{\text {th }}-12^{\text {th }}$ July 2012, Bangkok, Thailand.

Kepe T., Ntsebeza, L., \& Pithers, L. (2001) Agri-tourism spatial development initiatives in South Africa: are they enhancing rural livelihoods? Natural Resource Perspectives, PLAAS (programme for Land and Agrarian Studies), London: Overseas Development Institute, 65, 1-4.

Khan, M.M. (1997) Tourism Development and Dependency Theory: Mass Tourism vs. Ecotourism. Annals of Tourism Research, 24(4), 988-991

Kiss, A. (2004) Is Community-based Ecotourism a Good Use of Biodiversity Conservation Funds? Trends in Ecology and Evolution, 19, 231-237

Koch, E. (2004) Political economy, governance and community-based natural resource management. In Fabricius, C. (ed.) (2004) Rights, resources and rural development. Community-based natural resource management in Southern Africa. London: Earthscan, 78-92

Kontogeorgopoulos, N., Churyen, A., \& Duangsaeng, V. (2014) Success Factors in Community-Based Tourism in Thailand: The Role of Luck, External Support, and Local Leadership. Tourism Planning and Development, 11(1), 106-124

Lapeyre, R. (2010) Community-based tourism as a sustainable solution to maximise impacts locally? The Tsiseb Conservancy case, Namibia. Development Southern Africa, 27(5), 757-772

Lebowitz, M.A. (2004) Ideology and Economic Development. Monthly Review, 56(1), 14-24

Lefebvre, H. (2002) The Production of Space. Oxford: Blackwell.

Leksakundilok, A., \& Hirsch, P. (2008) Community-based tourism in Thailand. In Connell, J. \& B. Rugendyke (ed.) (2008) Tourism at the grassroot. Villagers and visitors in the Asia-Pacific. London: Routledge, 214-235
Li, WJ. (2006). Community decisionmaking. Participation in Development. Annals of Tourism Research, 33(1), 132-143.

Lima, S, García Gómez, C.S., Gómez López, D., \& Eusébio, E. (2012) El Turismo como una estrategia para el mundo en desarrollo: el ProgramaUNWTO. Volunteers. PASOS, Revista de Turismo y Patrimonio Cultural, 10(3), 303-314

Lindberg, K., Molstad, A., Hawkins D., \& Jamieson, W. (2001) International development Assistance in Tourism. Annals of Tourism Research, 28(2), 508-511.

Lukhele, S.E., \& Mearns, K.F. (2013) The operational challenges of community-based tourism ventures in Swaziland. African Journal for Physical, Health Education, Recreation and Dance, 2, 199-216

Manyara, G., \& Jones, E. (2007) Communitybased Tourism Enterprises Development in Kenya: An Exploration of Their Potential as Avenues of Poverty Reduction. Journal of Sustainable Tourism, 15(6), 628-644

Marx, S. (2011) Community-based tourism and pro-poor tourism. International Trade Forum, 2, 22.

Mayaka, M.A., Croy, G., \& Mayson, S. (2012) Community-based tourism: common conceptualisation or disagreement? Book of Proceedings the New golden Age of tourism and hospitality. Melbourne convention and exhibition centre. Book 2

Michot, T. (2010) Pro-Poor Tourism in Kumarakom, Kerala, South India: Policy Implementation and Impacts. Working Paper No. 7:1-24.

Mielke, E.J.C. (2012) Community-based tourism. Sustainability as a matter of results management. In Lohmann, G. \& D. Dredge (ed.) (2012) Tourism in Brazil. Environment, management and segments. London: Routledge, 30-43

Milne, S., \& Ateljevic, I. (2001) Tourism, economic development and the global-local nexus: theory embracing complexity. Tourism Geographies, 3(4), 369-393

Mitchell, R.E., \& Reid, D.G. (2001) Community integration. Island Tourism in Perú. Annals of Tourism Research, 28(1), 113-139

Mitchell, R.E. \& Eagles P.F.J. (2001) An Integrative Approach to Tourism: Lessons from the Andes of Peru. Journal of Sustainable Tourism, 9(1), 4-28 
Mitchell, J., \& Ashley, C. (2009) Can the private sector reduce poverty at scale? Evidence from the tourism value chain. The Commonwealth Ministers Reference Book. URL: $\quad$ http://www.odi.org.uk/resources/ download/3644.pdf (Accessed on 13.07.2011)

Mitchell, J., \& Ashley, C. (2010) Tourism and poverty reduction. Pathways to prosperity. London: Earthscan.

Mitchell, J. (2010) An unconventional but essential marriage: pro-poor tourism and the mainstream industry. Private Sector \& Development. Proparco's magazine, 7, 3-6

Mitchell, J., \& Muckosy, P. (2008) A misguided quest: Community-based tourism in Latin America. Overseas Development Institute, Opinion, 102.

Mitchell, R. E. \& Reid, D. G, (2001). Community integration. Island Tourism in Perú. Annals of Tourism Research, 28(1), 113-139.

Mohamad, N.H., \& Hamzah, A. (2012) Models of tourism cooperative for scaling up community based ecotourism: a case study of Miso Walai Homestay, Kinabatangan. Paper presentation at the Regional Symposium and Technical Day Tour on Rural Tourism, $18^{\text {th }}-19^{\text {th }}$ May 2012, Phnom Penh, Cambodia.

Mohan Mathur, H. (1995) The Role of Social Actors in Promoting Participatory Development at Local Level: A View from India. In Libercier, M.H. \& H. Schneider (ed.) (1995) Participatory development: from advocacy to action. Organisation for Economic Co-operation and Development, Development Centre Seminars. Paris: OECD, 153-170

Moscardo, G. (2008) Building community capacity for tourism development: conclusion. In Moscardo, G. (ed.) (2008) Building community capacity for tourism development. Wallingford: CAB International, 172-179

Mosedale, J. (2010) Re-introducing tourism to political economy. In Mosedale, J. (ed.) (2010) Political economy of tourism. A critical perspective. London: Routledge, 113

Mosedale, J. (2008) The internationalisation of tourism commodity chains. In Coles, T. \& C.M. Hall (ed.) (2008) International business and tourism. Global issues, contemporary interactions. London: Routledge, 149-166

Mowforth, M., \& Munt, I. (1998) Tourism and Sustainability New Tourism in the Third World. London: Routledge.

Mowforth, M., \& Munt, I. (2003) Tourism and Sustainability. Development and new tourism in the Third World. London: Routledge.

Mtapuri, O., \& Giampiccoli, A. (2013) Interrogating the role of the state and nonstate actors in community-based tourism ventures: toward a model for spreading the benefits to the wider community. South African Geographical Journal, 95(1), 1-15

Murphy, P.E., \& Andressen, B. (1988) Tourism development on Vancouver Island: an assessment of the core-periphery model. Professional Geographer, 40(1), 32-42

Nadkarni, S. (2008) Knowledge Creation, Retention, Exchange, Devolution, Interpretation and Treatment (K-CREDIT) as an Economic Growth Driver in Pro-Poor Tourism. Current Issues in Tourism, 11(5), 456-472

Naguran. R. (1999).Community based tourism in KwaZulu-Natal: Some Conceptual Issues. In Reid, D.G. (ed.) (1999) Ecotourism Development in Eastern and Southern Africa. Guelph: University of Guelph, 39-57

Nattrass, N. (1996) Gambling on investment: competing economic strategies in South Africa. Transformation, 31, 25-42

Navas-Camargo, F. \& Zwerg-Villegas, A. M. (2014). Community based tourism: is this progress? Revista Ciencias Estratégicas. 22(32), 249-259.

Ndlovu, N., \& Rogerson, C.M. (2003) Rural local economic development through community-based tourism: the Mehloding hiking and horse trail, Eastern Cape, South Africa. Africa Insight, 33, 124-129

Ndlovu, N., \& Rogerson, C.M. (2004) The local economic impacts of rural community-based tourism in Eastern Cape. In Rogerson, C.M. \& G. Visser (ed.) (2004) Tourism and development issues in contemporary South Africa. Pretoria: Africa Institute of South Africa, 436-451

Nelson, F. (2003) Community-based tourism in Northern Tanzania: Increasing opportunities, escalating conflicts and an uncertain future. Paper presented at the 
Association for Tourism and Leisure Education Africa Conference, $20^{\text {th }}-22^{\text {nd }}$ February 2003, Arusha, Tanzania

Ntshona, Z., \& Lahiff, E. (2003) CommunityBased Eco-Tourism on The Wild Coast, South Africa: The Case of the Amadiba Trail. SLSA Research Paper 7. Brighton: Institute of Development Studies (IDS).

NWT, (1983) Community-based tourism. A strategy for the Northwest Territories Tourism Industry. Department of Economic Development and Tourism, Government of the Northwest Territories, Yellowknife, N.W.T.

Nyaupane G.P., Morais, D.B., \& Dowler, L. (2006) The role of community involvement and number/type of visitors on tourism impacts: A controlled comparison of Annapurna, Nepal and Northwest Yunnan, China. Tourism Management, 27, 13731385

Nyerere, J. K. (1974) Ujama Essay on socialism. Dar es Salaam: Oxford University Press.

Okazaki, E. (2008) A Community-Based Tourism Model: Its Conception and Use. Journal of Sustainable Tourism, 16(5), 511529

Ostrom, E. (2000). Collective Action and the Evolution of Social Norms. Journal of Economic Perspectives, 14(3), 137-158.

Pearce, D. (1989) Tourism development. Harlow: Longman.

Peaty, D. (2007) Community-Based Ecotourism in Ecuador and Its Contributions to the Alleviation of Poverty. Human and Social Science of Ritsumekan University. URL: http://www.ritsumei.ac.jp/acd/re/k-rsc/hss/ book/pdf/no89_03.pdf 19.01.2014)

(Accessed

Peet, R. (2002) Ideology, Discourse and the Geography of Hegemony: From Socialist to Neoliberal Development in Postapartheid South Africa. Antipode, 34(1), 54-84

Peet, R. (2003) Unholy Trinity: The IMF, World Bank and WTO. London: Zed Book.

Peet, R., \& Watts, M. (1993) Introduction: Development Theory and Environment in the Age of Market Triumphalism. Economic Geography, 1, 227-253

Peredo, A.M. \& Chrisman, J.J. (2006) Toward a theory of community-based enterprise.
Academy of Management Review, 31(2), 309-328

Pérez, F.J., Barrera, O.D., Peláez, A.V., \& Lorío, G. (2010) Turismo Rural Comunitario Como Alternativa de educción de la Pobreza Rural en Centroamérica. Edificio Nitlapan Campus de la UCA Managua, Nicaragua.

Pinel, D.P. (1999). Create a good fit: A community-based tourism planning model. URL: http://nsgl.gso.uri.edu/washu/washuw 99003/28-Pinel.pdf (Accessed 22.05.2012)

Pleumaron, A. (2002) Community-Based Ecotourism: Miracle or Menace? Paper presented at IYE Regional Conference on Community-Based Ecotourism in Southeast Asia, $3^{\text {rd }}-7^{\text {th }}$ March 2002, Chiang Mai, Thailand

Posthumus, H. (2007) Can value chain development create rural employment and alleviate poverty? Enterprise Development and Microfinance, 18(2/3), 203-215

Pretty, J. (1995) The many interpretations of participation. In Focus, (16), 4-5

Pro-poor tourism partnership (PPTP). (2006) Pro-Poor Tourism: Annual Register. London: PPTP

Raffo, C. \& Wust, W. H, (n.d.) Communal Rural Tourism Peru: Successful experiences, from Perú. Prom Perú and Mincetur. URL: http://www.comeltur.com/docs/rural_tourism .pdf (Accessed 14.08.2015).

Reid, D.G. (2003) Tourism, globalisation and development: Responsible tourism planning. London: Pluto Press.

Richards, P. (2005) Community Based Tourism Marketing Training. CHARM-REST Partnership: Promoting Network of Community-Based Tourism (CBT) for Coastal Resources Management. European Union - Thailand Cooperation project Coastal Habitats and Resources Management THA/RELEX/2000/0050

(CHARM)

Roe, D. (2006) How pro-poor is tourism? New practices can reduce poverty. Id21 Insights, 62, 1-2.

Rogerson, C.M. (2009) Local economic development and tourism planning in Africa: evidence from route tourism in South Africa. In Hottola, P. (ed.) (2009) Tourism strategies and local response in Southern Africa. Wallingford: CAB International, 2740. 
Rogerson, C.M. (2012) The TourismDevelopment Nexus in sub-Saharan Africa Progress and Prospects. Africa Insight, 42(2), 28-45.

Rogerson, C.M., \& Visser, G. (2011) African tourism geographies: existing paths and new directions. Tijdschriftvoor Economische en Sociale Geografie, 102(3), 251-259.

Ruhiu, J.M. (2007) Capital for investing in community based tourism (cbt) - grants vs loans. Presented at the National Ecotourism Conference, $22^{\text {nd }}-24^{\text {th }}$ October 2007, Panafric Hotel, Nairobi, Kenya.

Russell, E., \& Kuiper, S. (2003) The Amadiba Community Tourism and Natural resource management project. In Hauck, M. \& M. Sowman (ed.) (2003) Waves of Change. Cape Town: University of Cape Town Press, 147-174.

Saayman, M. (2009) Community tourism. In Saayman, M. (ed.) (2009) Ecotourism. Getting back to basic. Potchefstroom: Institute for tourism and Leisure Studies, 6796.

Saayman, M. \& Giampiccoli, A. (2015) Community-based tourism and pro-poor tourism: dissimilar positioning in relation to community development. Journal for New Generation Sciences, 13(3), 163-181

Saayman, M., Rossouw, R., \& Krugell, W. (2012) The impact of tourism on poverty in South Africa. Development Southern Africa, 29(3), 462-487.

SAF - South African Foundation (2003) Cooperatives in South Africa: Their Role in Job Creation and Poverty Reduction. Occasional paper No2/2003.Johannesburg: South Africa Foundation.

Sakata, H. \& Prideaux, B. (2013) An alternative approach to community-based ecotourism: a bottom-up locally initiated non-monetised project in Papua New Guinea. Journal of Sustainable Tourism, 21:6, 880-899.

Sammy, J. (2008) Examples of effective techniques for enhancing community understanding of tourism. In Moscardo, G. (ed.) (2008) Building community capacity for tourism development. Wallingford: $\mathrm{CAB}$ International, 75-85.

SATOUR - South African Tourism. (2010) Annual Tourism Report 2009. South African Tourism Strategic Research Unit. URL: http://www.southafrica.net/sat/action/media/
downloadFile? media fileid $=29853$

(Accessed 16.08.2011)

Scheyvens, R. (2011) Tourism and poverty. London: Routledge.

Scheyvens, R., \& Russell, M. (2012) Tourism and poverty alleviation in Fiji: comparing the impacts of small- and large-scale tourism enterprises. Journal of Sustainable Tourism, 20(3), 417-436

Scheyvens, R., \& Russell, M. (2010) Sharing the Riches of Tourism. Summary Report Fiji Massey University, School of People, Environment \& Planning.

Scheyvens, R. (1999) The potential for ecotourism to facilitate the empowerment of local communities in Southern Africa. A summary report using selected case studies. New Zealand: Massey University.

Scheyvens, R. (2002). Tourism for Development Empowering Community. Prentice Hall, Harlow.

Scheyvens, R. (2007). Exploring the TourismPoverty Nexus. In Hall, M. (ed.) (2007) Propoor tourism: who benefits? Perspective on tourism and poverty reduction. Clevedon: Channel View Publications, 121-144

Schilcher, D. (2007) Growth versus equity: the continuum of pro-tourism and neoliberal governance. In Hall, M. (ed.) (2007) Propoor tourism: who benefits? Perspective on tourism and poverty reduction. Clevedon: Channel View Publications, 56-83

Seers, D. (1969) The Meaning of Development. International Development Review, 11(4), 26

Sharpley, R. (2002) Tourism: a vehicle for development? In Sharpley, R. \& D.J. Telfer (ed.) (2002) Tourism and Development Concepts and Issues. Clevedon: Channel View Publications, 11-34

Simpson, M.C. (2008) Community Benefit Tourism Initiatives: A conceptual oxymoron? Tourism Management, 29, 1-18

Singh, L.K. (2008) Ecology, Environment and Tourism. ESHA Books: Delhi.

Slocum, S.L., \& Backman, K.F. (2011) Understanding Government Capacity in Tourism Development as a Poverty Alleviation Tool: A Case Study of Tanzanian Policy-Makers. Tourism Planning and Development, 8(3), 281-296

SNV, 2011. Pro-poor perspectives in the tourism sector in Rwanda. Capitalization of 
SNV's Capacity Development Services 2005-2011. Netherlands Development Organisation. URL: http://www.snvworld.org/en/publications/propoor-perspectives-in-the-tourism-sector-inrwanda (Accessed 14.08.2015).

Twining-Ward, L. (2007) A Toolkit for Monitoring and Managing Community-based Tourism. Netherlands Development Organisation (SNV) and University of Hawaii, School of Travel Industry Management.

Sofield, T.H.B. (2003) Empowerment for sustainable tourism development. Oxford: Pergamon.

Stone, D. (2000) Non-Governmental Policy Transfer: The Strategies of Independent Policy Institutes. Governance: An International Journal of Policy and Administration, 13(1), 45-62

Suansri, P. (2003) Community Based Tourism Handbook. Bangkok: Responsible Ecological Social Tour (REST).

Suryia, K. (2010) Impact of Community-based Tourism in a Village Economy in Thailand: An analysis with VCGE model. URL: http://ecomod.net/sites/default/files/docume nt-conference/ecomod2010/1302.pdf (Accessed 27.07.2012)

Telfer, D.J. (2002) The evolution of tourism and development theory. In Sharpley, R. \& D.J. Telfer (ed.) (2002) Tourism and Development Concepts and Issues. Clevedon: Channel View Publications, 3578

Telfer, D.J., \& Sharpley R. (2008) Tourism and Development in the Developing World. London: Routledge.

Telfer, D.J. (2009) Development studies and tourism. In Jamal, T. \& M. Robison (ed.) (2009) The SAGE handbook of tourism studies. London: SAGE Publications, 146165

Tewari, D. D. (2011) Wealth creation through mass capital mobilization through a cooperative enterprise model: Some lessons for transplanting the Indian experience in South Africa. African Journal of Business Management, 5(22), 8980-8989

Timothy, D. (2002) Tourism and community development issues. In Sharpley, R. \& D.J. Telfer (ed.) (2002) Tourism and Development Concepts and Issues.
Clevedon: Channel View Publications, 135178

Tosun, C. (2000) Limits to community participation in the tourism development process in developing countries. Tourism Management, 21, 613-633

Turner, R. (2006) Communities, Conservation, and Tourism-Based Development: Can Community-Based Nature Tourism Live Up to Its Promise? URL: http://escholarship.org/uc/item/0fq311pw (Accessed 11.08.2011)

ul Haque I. (2004) Commodities under Neoliberalism: The Case of Cocoa. URL: http://www.unctad.org/en/docs/gdsmdpbg24 20041_en.pdf (Accessed 11.08.2011)

Van der Duim, R. (2008) Exploring pro-poor tourism research: The state of the art. In de Haan, H. \& R. Van der Duim (ed.) (2008) Landscape, leisure and tourism, Sociospatial studies in experiences, practices and policies. Delft: Eburon Academic Publishers, 179-198

Van der Walt, L. (2008) Collective entrepreneurship as a means fro sustainable community development: a cooperative case study, Forum Empresarial 13(2), 3-20

Victurine, R. (2000) Building Tourism Excellence at the Community Level: Capacity Building for Community-Based Entrepreneurs in Uganda. Journal of Travel Research, 38, 221-229

Wallace, W. (2004) Afterwords: soft power, global agendas. In Stone, D. \& A. Denham (ed.) (2004) Think Tank Traditions: Policy research and the politics of ideas. Manchester: Manchester University Press, 281-290

Wearing, S., \& McDonald, M. (2002) The Development of Community-based Tourism: Re-thinking the Relationship between Tour Operators and Development Agents as Intermediaries in Rural and Isolated Area Communities. Journal of Sustainable Tourism, 10(3), 191-206

Webster, C., S. Ivanov (2012) The political economy of tourism in the future. In Leigh, J., C. Webster and S. Ivanov (eds.) Future Tourism: Political, Social and Economic Challenges, London: Routledge, pp. 21-34.

Webster, C \& Ivanov, S. H. 2013. Characterizing the Policies and Programs of 
National Tourism Organizations: Liberal, Mercantilist, Communist, and Social Democratic Approaches to Tourism Development and Management. Paper presented at the International Conference on Tourism (ICOT2013) "Trends, Impacts and Policies on Sustainable Tourism Development", Limassol, Cyprus 5-8 June 2013

Wehkamp, A. (2007) Preface. In L. TwiningWard (Ed.), A Toolkit for Monitoring and Managing Community-based Tourism. Netherlands Development Organisation (SNV) and University of Hawaii, School of Travel Industry Management.

WHO, no date. Neo-Liberal Ideas. URL: http://www.who.int/trade/glossary/story067/e $\mathrm{n} /$ (Accessed 08.08.2015).

Williams, R. (1976). Base and superstructure in Marxist cultural theory. In Schooling and Capitalism. A sociological reader, R. Dale, G. Esland, and M. MacDonald, eds., pp. 202-210. Maidenhead: The Open University Press.

Williams, A.M. \& Montanari, A. (1999) Sustainability and self-regulation: critical perspectives. Tourism Geographies, 1(1), $26-40$
Wood, R.E. (2009) Tourism and international policy: neoliberalism and beyond. In Jamal, T. \& M. Robinson (ed.) (2009) The Sage handbook of Tourism studies. London: Sage, 595-612

Wright, B.B. (2005) A review of lessons learned to inform Capacity-building for sustainable nature based Tourism development in the European Union funded 'support to the wild coast Spatial development initiative pilot Programme'. Half-thesis submitted in partial fulfilment of the requirements for the degree of Masters of Education (Environmental Education), Rhodes University.

Ypeij A and Zorn E. 2007. Taquile: A Peruvian Tourist Island Struggling for Control. European Review of Latin American and Caribbean Studies, 82, 119-128.

Zajda, J. (2011) Globalisation and schooling: equity and access issues. Cultural Studies of Science Education, 6, 143-152

Zapata, M.J., Hall, M.C., Lindo, P., \& Vanderschaeghe, M. (2011) Can community-based tourism contribute to development and poverty alleviation? Lessons from Nicaragua. Current Issues in Tourism, 14 (8), 725-749 